\title{
Critical Review of the Use of Second-Generation Antipsychotics in Obsessive-Compulsive and Related Disorders
}

\author{
Dongmi Kim $^{1}$ (D) Nicole L. Ryba ${ }^{1}$. Julie Kalabalik ${ }^{1} \cdot$ Ligia Westrich $^{1}$
}

Published online: 31 August 2018

(c) The Author(s) 2018

\begin{abstract}
Currently, all second-generation antipsychotics are approved for schizophrenia. Many are also approved for bipolar disorder, with some also approved as adjunctive treatment for depression and autism-related irritability. Second-generation antipsychotics are increasingly being prescribed for indications other than those approved by the Food and Drug Administration, such as in dementia, anxiety, and post-traumatic stress disorder to name a few. Obsessive-compulsive and related disorders are a group of disorders characterized by preoccupation and repetitive behaviors. According to the latest edition of the Diagnostic and Statistical Manual of Mental Disorders, obsessive-compulsive disorder, body dysmorphic disorder, trichotillomania, hoarding disorder, and excoriation, the latter two being newly designated disorders, fall under obsessive-compulsive and related disorders. Due to a lack of well designed clinical studies specifically addressing the use of second-generation antipsychotics in obsessive-compulsive and related disorders, it is unknown whether these agents are clinically beneficial. Current research describing the pathophysiology of these disorders shows the involvement of similar brain regions and neurotransmitters across the five obsessive-compulsive and related disorders. Despite differences in the receptor binding profiles, second-generation antipsychotics share many common pharmacodynamics properties. This review sought to examine all the published reports of second-generation antipsychotics being used in the management of symptoms of the aforementioned diseases and compile evidence for clinicians who encounter patients who are unresponsive to standard treatment.
\end{abstract}

Dongmi Kim

dongmi@fdu.edu

1 Fairleigh Dickinson University School of Pharmacy and Health Sciences, Florham Park, NJ, USA

\section{Key Points}

Obsessive-compulsive disorder, body dysmorphic disorder, trichotillomania, hoarding disorder, and excoriation are characterized by preoccupation and repetitive behavior, and are classified under 'obsessive-compulsive and related disorders' (OCRDs) in the latest edition of the Diagnostic and Statistical Manual of Mental Disorders.

A trial of second-generation antipsychotics is reserved as a third-line option for patients with treatment-refractory obsessive-compulsive disorder and body dysmorphic disorder. There is no consensus on the trial of these agents in trichotillomania, hoarding disorder, and excoriation.

Aripiprazole and risperidone may confer the most benefit across all the treatment-refractory OCRDs. The metabolic adverse effects of the second-generation antipsychotics, notably olanzapine, may outweigh the benefit of symptom improvement in OCRDs. Well designed studies are needed to inform evidence-based therapy in OCRDs. 


\section{Introduction}

Obsessive-compulsive and related disorders (OCRD) are a group of disorders that affect a wide range of ages in both genders worldwide. This group includes obsessive-compulsive disorder (OCD), body dysmorphic disorder (BDD), hoarding disorder (HD), trichotillomania (hair-pulling disorder, TTM), excoriation (skin-picking disorder, ExD), substance/medication-induced OCRD, OCRD due to another medical condition, and other specified OCRDs [1]. OCRDs were categorized under anxiety disorders or impulse control disorders in the 4th edition of the Diagnostic and Statistical Manual of Mental Disorders (DSM-IV-TR). The authors of the DSM-5 sought to maximize clinical utility and diagnostic validity by grouping these disorders together based on similar phenotype and underlying pathophysiology [2]. DSM-5 also made another important distinction: the inclusion of a degree of insight specifier, the degree of an individual's conviction into an obsessive thought. Delusional OCRD with poor/ absent insight was previously classified as a psychotic or delusional disorder, for which the preferred pharmacological therapy would have been an antipsychotic [3].

OCD is a chronic and disabling disorder characterized by recurrent, intrusive, and irresistible thoughts (obsession) and repetitive behavioral or mental acts that are performed in response to these thoughts (compulsion). This disorder is reported to affect $1-2 \%$ of the general population and 1-3\% of children and adolescents [4]. Diagnosis is often difficult because an individual may not have any outward evidence of compulsive acts or may lack insight into the inappropriateness of the disorder and subsequently fail to seek treatment. Once the diagnosis is made, the symptoms are assessed using a rating scale such as the Yale-Brown Obsessive-Compulsive Scale (Y-BOCS) [5].

BDD is a preoccupation with imaginary or slight defects in appearance. BDD in males often presents with distinctive features such as excessive weight-lifting, excessive dieting, and higher rates of suicide compared with other OCRD. Females with BDD are preoccupied with breasts, hips, weight and legs that reflect the values of the culture and the media. The perceived physical defect may be vague or specific and involves one or multiple parts of the body. There is a high comorbidity rate between BDD and OCD, ranging from 8 to $37 \%$ lifetime rates in select studies [6]. The recurrent thoughts about physical defects and repetitive behavior (e.g., viewing oneself in a mirror or 'self-surgery') found in patients with BDD may resemble the characteristics of OCD. Patients with BDD suffer from low self-esteem and strongly believe that the only way to improve is to change the way they look. As a result, many patients with BDD often seek beauty remedies or plastic surgery [7]. Symptoms of BDD may be assessed in clinical studies using a clinician-rated instrument known as BDD-Y-BOCS, a modified version of Y-BOCS [8].

OCRDs also include TTM, also known as hair-pulling disorder. Though larger epidemiological data are missing, it is known to affect $0.6 \%$ of college students [9]. TTM occurs more in females than in males (4:1) and is characterized by recurrent hair pulling that leads to hair loss and functional impairment. Some $5-20 \%$ of cases develop trichophagia, oral consumption of hair after pulling. Hair pulling may be preceded by anxiety; this anxiety builds toward the pulling of hair and is followed by relief upon the act. Co-occurrence with OCD is common, ranging from 13 to $27 \%$ [10]. Care should be taken in diagnosis since trichotillomania may be misdiagnosed as OCD due to the repetitive behavior; however, there are seldom intrusive thoughts that lead to the hair-pulling behavior. For symptom assessment, Massachusetts General Hospital Hair Pulling Scale (MGHHPS) is a seven-item self-report instrument that rates severity in urges to pull, actual pulling, perceived control, and associated distress [11].

In ExD, also known as psychogenic excoriation (PE), individuals squeeze, dig, rub or lance either healthy or distressed skin, resulting in infection. Negative emotional states are present prior to (e.g., anxiety, tension) and after (e.g., shame, guilt) skin picking; relief/gratification after picking has been noted. Skin-picking behaviors may occur as a response to perceived bodily defect as in BDD. Disease progression or improvement can be monitored through use of a modified version of an existing rating scale for OCD (Y-BOCS modified for neurotic excoriation) or via self-rating by use of one of several scales, such as the Skin Picking Scale [12]. ExD is a new disorder in DSM-5.

In HD, individuals have persistent difficulty in parting with possessions. These individuals acquire materials for which there is no need or for which there is no space for storing. This clutters their own space and sometimes clutters the space of family members or neighbors. HD is best diagnosed by conducting a clinical interview at a person's home, where the clutter and the associated impairment are visible. HD was previously a symptom of OCD (DSM-IV TR), but is a newly created, stand-alone disorder in DSM-5 [13].

Limited to OCD and BDD, serotonergic medications are recommended as the preferred pharmacological agents. According to the treatment guideline updated in 2010 by the American Psychiatric Association, after adequate trial of selective serotonin reuptake inhibitors (SSRIs) or clomipramine, patients whose OCD remain unresponsive may be considered for augmentation with cognitive behavioral therapy (CBT) or with an antipsychotic [14]. The UK guidelines on OCD and BDD, published in 2005, recommend SSRIs for both disorders; in cases of unresponsive disease, the next step is to combine with CBT or to switch to clomipramine. 
Antipsychotics are reserved as third-line augmentation agents for disorders that are difficult to treat [15]. Based on a recent Cochrane analysis, there is no single medication class that seems to be effective in reducing symptoms of TTM [16]. There is limited evidence that SSRIs may be helpful for HD [13]. No major organization has put forth treatment guidelines for TTM, HD, and ExD. Moreover, there are no specific guidelines for OCRDs. The authors recognize the need for an update in literature to assist clinicians to formulate evidence-based pharmacotherapeutic recommendations for patients who minimally respond to the commonly used medication therapy in OCRDs. The review herein presents current evidence for the use of second-generation antipsychotics (SGAs) for all treatment-resistant OCRDs in adult patients.

A literature search was conducted using Medline, PsychInfo and the Cochrane Library database for all clinical trials, case series, and case reports that were published in English up to January 2018. Due to the scarcity of published evidence, all were included in the review. It must be noted that the evidence from uncontrolled trials and case reports are much weaker than randomized controlled trials, but were included for the completion of the review. The search was done with the names of each antipsychotic (e.g., 'olanzapine,' 'quetiapine'), and the disease terms were matched with the MeSH terms (e.g., 'obsessive-compulsive disorder,' 'trichotillomania,' 'hoarding,' 'body dysmorphic disorders'). Excoriation was entered as a search term as there is no MeSH term for this disorder. The following inclusion criteria were applied: adult patients ( $\geq 18$ years old), DSM-based diagnosis of any of the OCRDs (comorbidity was acceptable other than psychosis), SGA being initiated or used for the treatment of any OCRD, and manuscript published in English. We excluded pediatric or adolescent populations ( $<18$ years old), lack of DSM-based diagnosis of any OCRD in the studied population, and publications of SGA associated or induced OCRD. Initial screening yielded 1049 manuscripts. After reviewing the title and the abstract, 913 manuscripts were deemed to not meet the inclusion criteria and were removed from the final selection. Finally, 136 manuscripts fulfilled the inclusion criteria and comprised this review (Table 1).

\section{Etiology and Pathophysiology}

Integral parallel basal ganglia-thalamocortical circuits regulate normal goal-directed behaviors. These circuits include the direct and indirect dopaminergic pathways, which roughly represent the dorsal basal ganglia involved in motor and cognitive behaviors and the ventral-basal ganglia involved in affective- and reward-based behaviors, respectively. The dorsal circuit (cognition) modulates the output
Table 1 Review process and publication selection

\begin{tabular}{lrc}
\hline Drug names & Initial screening & $\begin{array}{c}\text { Included in } \\
\text { this review }\end{array}$ \\
\hline Aripiprazole & 110 & 35 \\
Asenapine & 4 & 0 \\
Brexpiprazole & 1 & 0 \\
Cariprazine & 0 & 0 \\
Clozapine & 299 & 4 \\
Iloperidone & 5 & 0 \\
Lurasidone & 1 & 0 \\
Olanzapine & 282 & 43 \\
Paliperidone & 10 & 1 \\
Pimavanserin & 0 & 0 \\
Quetiapine & 102 & 24 \\
Risperidone & 212 & 28 \\
Ziprasidone & 23 & 2 \\
TOTAL & 1049 & 136 \\
\hline
\end{tabular}

of the ventral circuit (emotional behaviors) [17-19]. It is hypothesized that an increase in the activity of the ventral circuit results in increased anxiety and repetitive behaviors, while a decrease in activity of the dorsal circuit results in reduced ability to regulate emotional-based activities [17, 20-22]. The inability to inhibit and regulate learned automated behaviors can result in repetitive, compulsive behaviors such as OCD, obsession with various parts of self (BDD) or belongings (HD), hair pulling (TTM), and skin picking (ExD).

Genetic and environmental factors contribute to the etiology of OCRD. BDD and OCD share common features. BDD and OCD are comorbid, therefore genetic association studies have been performed to understand the etiology and pathophysiology of these disorders. In addition, heredity studies have found that $7 \%$ of patients with BDD have a first-degree relative with OCD, while first-degree relatives of patients with OCD have a six times higher risk of developing BDD compared with controls [23]. While $75 \%$ of individuals with HD have a co-occurring anxiety or mood disorder, only $20 \%$ of individuals who meet the criteria for HD also meet the criteria for OCD [1].

TTM and ExD share common features. Neuroimaging studies show that connectivity within and between brain regions, such as basal ganglia, cerebellum, and cortical motor areas, involved in formation of motor habits are affected in TTM [10] and ExD [24]. Activity in these areas and inhibitory processes may be faulty. Both white and grey matter are involved.

Several structural and functional neuroimaging studies have also been conducted to investigate the role of various brain regions (inferior frontal cortex, right parietal cortex, orbito-frontal cortex, occipito-temporal cortex, insula, 
striatum, and amygdala) thought to be involved in the regulation of emotional behaviors in OCRD $[25,26]$. The mean volumes of the orbito-frontal and anterior cingulate cortices of unmedicated BDD patients were found to be significantly smaller than those of healthy controls [27]. Decreased activation of the dorsal striatum, anterior cingulate cortices and right frontal regions has been observed in patients with ExD who performed an executive planning task (Tower of London) during functional magnetic resonance imaging (fMRI) [28]. When interpreting these studies, it is important to consider compensatory mechanisms (induced by exposure to the environment and therapies) that may shape the size and function of affected brain areas in OCRD.

\section{Pharmacology of Second-Generation Antipsychotics (SGAs)}

In general, SGAs, also known as atypical antipsychotics, work by blocking serotonin and dopamine receptors. In vitro studies have shown that asenapine, olanzapine, risperidone, paliperidone, ziprasidone, lurasidone, and iloperidone are antagonists at serotonin 5-HT2A/1A, dopamine D2/3, histamine $\mathrm{H} 1$, and $\alpha$ adrenergic receptors. They display slightly higher affinity for 5-HT2A than D2 receptors [29]. Aripiprazole and brexpiprazole are partial agonists at D2/D3 receptors and 5-HT1A, and antagonists at 5-HT2A, 5-HT2B, 5-HT2C, 5-HT7, H1, and $\alpha 1$ receptors. They have the highest affinity for D2/3 and 5-HT2B receptors, with additional significant affinity for 5-HT1A, 2A, H1, and $\alpha 1$ receptors [30-32]. Quetiapine and its metabolite, N-desalkylquetiapine, are antagonists at serotonin, dopamine, histamine, muscarinic and $\alpha$-adrenergic receptors, in addition to inhibiting the norepinephrine transporter. They have the highest affinity for $\mathrm{H} 1$ receptors, followed by significant affinity for the norepinephrine transporter, 5-HT1A, and 5-HT1B, among other serotonin, adrenergic and muscarinic receptor subtypes [33]. In contrast with most aforementioned SGAs, clozapine has high affinity for D4 receptors and not for D2 receptors. In addition, clozapine has significant affinity for 5-HT2A, 5-HT2C, 5-HT6, 5-HT7, M1 and $\alpha 1$ receptors [34, $35]$.

\section{Obsessive-Compulsive Disorder (OCD)}

\subsection{Aripiprazole}

Aripiprazole is the first marketed antipsychotic with D2 partial agonist activity. While the earliest published study by Connor and colleagues examined aripiprazole monotherapy in OCD, all the subsequent trials were add-on in treatment-resistant OCD, that is, serotonin-reuptake inhibitor (SRI) resistant [36-42].

\subsubsection{Evidence from Randomized Controlled Trials}

Two double-blinded trials, one by Sayyah and colleagues and another by Muscatello and colleagues, differentiated aripiprazole from placebo after 12 weeks of intervention [38, 39]. First, in the study by Sayyah and colleagues, 39 patients were randomized to receive either aripiprazole $10 \mathrm{mg}$ /day or placebo. Any patient with prominent psychiatric comorbidity was excluded from the study. The mean Y-BOCS score at baseline was 22.21 in the aripiprazole group and 24.12 for the placebo group. After 12 weeks of blinded intervention, the resulting Y-BOCS score was 15.42 in the aripiprazole group and 23.12 in the placebo group $(p<0.0001)$. Sedation was more commonly reported from the patients receiving aripiprazole (four patients in the aripiprazole group and two in the placebo group) [39]. Muscatello and colleagues conducted a double-blind, placebo-controlled trial of aripiprazole augmentation in serotonin reuptake inhibitor (SRI)-refractory OCD (fluvoxamine, fluoxetine, citalopram, paroxetine, or clomipramine). Thirty patients were randomized to receive either aripiprazole $(15 \mathrm{mg} /$ day) or placebo. While change in Y-BOCS score was the primary objective, neurocognitive function was measured using various tools as secondary objectives (the Wisconsin Card Sorting Test, the Verbal Fluency Task-Controlled Oral Word Association Test and the Stroop Color-Word Test). Baseline Y-BOCS score was 23.23 in the aripiprazole group and 23.60 in the placebo group. After 12 weeks of blinded intervention, the mean Y-BOCS score in the aripiprazole group was 16.31 while there was no reduction observed in the placebo group $(p<0.0001)$. As a secondary outcome analysis, there was a clear trend toward improved neurocognitive functioning in the patients receiving aripiprazole. Restlessness $(n=7)$ and insomnia $(n=2)$ were frequently reported in the aripiprazole group [38].

Two head-to-head trials have been published for aripiprazole in the management of treatment-resistant OCD. In a study by Selvi and colleagues, aripiprazole was compared with risperidone as augmenting agents for SRI-resistant OCD. In this single-blind, randomized study, patients who did not show a $\geq 35 \%$ decrease in the Y-BOCS scores after 12-week monotherapy with an SRI were randomized to an 8 -week single-blind additional period in which refractory patients received either risperidone $3 \mathrm{mg}$ daily or aripiprazole $15 \mathrm{mg}$ daily as augmentation to SRI treatment. Of 41 patients, $50 \%$ of aripiprazole and $72.2 \%$ of risperidone patients met the response criteria of Y-BOCS decrease $\geq 35 \%$ at the end of the study. Mean Y-BOCS total scores between the two groups at weeks 12 and 20 were significant and favored risperidone $(r(32)=2.115, p<0.05 ; t(32)=2.675$, 
$p<0.05)$. Y-BOCS Obsessions subscale results favored risperidone at weeks 12 and $20(t(32)=2.417, p<0.05$; $t(32)=2.630, p<0.05)$ [43]. The second head-to-head trial was carried out with aripiprazole and quetiapine as augmenting agents to an ongoing SSRI. In total, 44 female patients were randomized and received blinded treatment of quetiapine (maximum $300 \mathrm{mg} /$ day) or aripiprazole ( $10 \mathrm{mg} /$ day) for 12 weeks. The mean Y-BOCS score reduction in the quetiapine group was 3.31 (from 31.18 to $27.97, p=0.01$ ) and 2.45 in the aripiprazole group (from 33.17 to $30.72, p=0.06$ ), of which clinical significance is unclear [44].

\subsubsection{Evidence from Uncontrolled Trials}

Open-label trials were of moderate size (ranging 10-40) and used an aripiprazole dose of at least $10 \mathrm{mg} /$ day for a maximum of 12 weeks $[36,37,40]$. The reductions in Y-BOCS score were moderate in these trials. Delle Chiaie and colleagues conducted an open-label study to test the efficacy of aripiprazole in patients with refractory OCD. After excluding patients with any major psychiatric comorbidity or laboratory abnormalities, 20 patients were enrolled to receive aripiprazole (mean dose $12.62 \mathrm{mg} /$ day) for 12 weeks. Treatment outcome was measured by Y-BOCS score and Clinical Global Improvement-Severity scale (CGI-S). Full response was defined as $\geq 35 \%$ reduction in the Y-BOCS score. After 12 weeks, mean Y-BOCS score was reduced from 28.99 (baseline) to $15.55(p=0.0001)$ and CGI-S was reduced from 5.1 (baseline) to $2.55(p=0.0001)$ [40].

\subsubsection{Case Series and Case Reports}

Two case series were reported from patients who failed not only one or more SSRI but also one or more augmenting antipsychotic [41, 45]. Aripiprazole augmentation resulted in mean Y-BOCS score reduction of at least $30 \%$ (combined, $n=74$ completers). These results suggest that aripiprazole may act uniquely as a partial D2 agonist against pathology of severe OCD.

There have been a number of published case reports describing the successful use of adjunctive aripiprazole in the management of severe OCD [46-60]. Patients with different comorbidities have been successfully treated, notably comorbid bipolar disorder [47, 55, 60], major depressive disorder [52, 61], Tourette syndrome [62], and ExD [50]. In cases of OCD with comorbid bipolar disorder, the challenge for the clinician is the relative contraindication to antidepressants due to the possible risk of switching to a manic episode. In the three published cases, aripiprazole was added to a high-dose mood-stabilizing medication, such as lithium, and the patients experienced clinical improvement [47, 55, 60]. Aripiprazole monotherapy has also been reported [61, 62]. Successful use of aripiprazole in OCD with poor insight or with delusion may be of clinical interest, as aripiprazole is an SGA that would be indicated for psychotic disorders $[48,56]$.

Based on the reviewed evidence, aripiprazole is effective in treating SSRI-resistant OCD, though less efficacious than risperidone.

\subsection{Clozapine}

\subsubsection{Evidence from an Uncontrolled Trial}

McDougle and colleagues illustrated a 10-week, open-label trial of adult patients with refractory OCD treated with clozapine as monotherapy [63]. Twelve patients (6 women, 6 men; mean age 34.8 years) received flexible dosing of clozapine $300-600 \mathrm{mg} /$ day (mean dose $462.5 \mathrm{mg} /$ day) for a minimum of 8 weeks after a 3 -week wash-out period of any other psychotropic medications. Patients were included if their OC symptoms were of moderate severity on the CGI scale for at least 2 years and were refractory, defined as a Y-BOCS score of $\geq 16$ or $<35 \%$ improvement, no better than minimal improvement on Clinical Global Impression-Improvement (CGI-I) scale, and consensus of no improvement by the primary investigators. Additionally, the patient also had to be refractory to a clomipramine dose of at least $200 \mathrm{mg} /$ day, a fluoxetine dose of at least $60 \mathrm{mg} /$ day, or a fluvoxamine dose of at least $200 \mathrm{mg}$ /day for a minimum of 8 weeks, a combination of clomipramine, fluoxetine, or fluvoxamine with a typical neuroleptic for a minimum of 4 weeks, and a trial of behavioral therapy while receiving medication. Response criteria after initiation of clozapine was defined as $>35 \%$ improvement on Y-BOCS scale and final score $<16$, a final CGI rating of 'much improved' or 'very much improved', and a consensus of patient improvement by all primary investigators. Ten patients $(83 \%)$ completed the trial, of which none met criteria for responders. Two patients discontinued the trial early due to adverse events of sedation and hypotension.

\subsubsection{Case Reports}

Two case reports $(n=2)$ demonstrated the use of clozapine for treatment of refractory OCD as monotherapy [64, 65]. Case 1 was a 21-year-old White male who was determined to have treatment refractory OCD after 17 medication trials, electroconvulsive therapy, and other procedures that were all unsuccessful at alleviating his compulsions. After years of failure, the patient was started on clozapine and titrated up to $600 \mathrm{mg} /$ day. A reduction in compulsions was noted, as well as a decrease in score on the Y-BOCS from 36 to 19 at 4 months of treatment [64]. Similarly to the previous case in the number of treatment failures, Case 2 represented a 27 -year-old female who was treated with 14 different 
combinations of SRIs and neuroleptics over 9 years without relief of her aggressive and violent compulsions. The patient was started on clozapine and titrated up to $400 \mathrm{mg} /$ day. This case also noted a decrease in compulsions, as well as a decrease in her Y-BOCS score from 35 to 18 after 3 weeks of treatment [65]. No significant side effects were reported in either of the cases.

Mixed results were observed in the data when clozapine was utilized as monotherapy for treatment of refractory OCD. Though McDougle et al. showed no improvement in their patient population, it should be noted that positive results were seen in the case reports, which represented patients who had a longer history of treatment failure [63-65].

\subsection{Olanzapine}

\subsubsection{Evidence from a Randomized Controlled Trial}

Shapira et al. demonstrated a double-blind, placebo-controlled trial of olanzapine added to fluoxetine in patients with refractory OCD [66]. Patients with a diagnosis of OCD for a minimum of 1 year entered the study $(n=74)$ and initially underwent a trial of fluoxetine titrated to $40 \mathrm{mg}$ daily and maintained over 8 weeks. A total of 44 patients (18 male, 26 female; mean age $36.9 \pm 11.1$ years) were deemed nonresponders or partial responders to fluoxetine therapy and underwent randomization to receive olanzapine treatment $(n=22)$ or placebo $(n=22)$ in addition to fluoxetine. Both groups demonstrated a significant improvement in their Y-BOCS scores (mean decrease of olanzapine: $5.1 \pm 4.9$ and placebo: $3.8 \pm 3.8, p<0.0001$ ) over 6 weeks of treatment. A total of four patients, two in each group, discontinued treatment due to adverse events. Weight gain was observed more in the olanzapine plus fluoxetine group.

\subsubsection{Evidence from Uncontrolled Trials}

Maina and colleagues conducted a two-phase trial to analyze the efficacy and safety of risperidone and olanzapine augmentation therapy in patients with treatment-resistant OCD [67]. Patients were enrolled in the first phase if they met criteria for OCD with symptoms present for at least 1 year and had a Y-BOCS score $\geq 16$. These patients $(n=96)$ were entered into a 16-week open-label phase where they received treatment with an SSRI for at least 12 weeks. If patients did not show improvement in their Y-BOCS score or score $\leq 2$ on the CGI-I scale, they were considered non-responders and entered into the second single-blind, 8-week phase of the trial. Fifty patients $(52 \%)$ were considered SSRI-resistant after phase 1 and titrated on risperidone $1 \mathrm{mg}$ daily $(n=25$; mean daily dose $2.1 \pm 0.6 \mathrm{mg} /$ day, $\max 3 \mathrm{mg} /$ day) or olanzapine $5 \mathrm{mg}$ daily $(n=25$; mean daily dose $=5.3 \pm 2.6 \mathrm{mg}$ / day, $\max 10 \mathrm{mg} /$ day). Twenty-two patients (88\%) in the risperidone group and 21 patients $(84 \%)$ in the olanzapine group completed the trial. Patients within each group demonstrated a significant improvement from baseline in the mean total Y-BOCS score ( $p<0.001$, both), obsession and compulsion subscores $(p<0.001$, both) and in the analysis of CGI-S scores $(p<0.001$, both). No differences were detected in the efficacy between both treatment groups at any point in time. Adverse events were seen in both groups, $52 \%(n=13)$ with risperidone and $64 \%(n=16)$ with olanzapine, with the only statistically significant event being increased weight gain with olanzapine (mean $2.8 \pm 3.10$ vs $0.77 \pm 2.16 \mathrm{~kg}$; $p=0.10$ ).

Mixed results were seen when augmenting an SSRI with a SGA in SSRI-refractory OCD patients. Matsunaga et al. conducted a trial to assess the long-term safety and efficacy of augmenting an SSRI with an SGA in this patient population [68]. A total of 137 patients with a diagnosis of OCD were initially assigned to receive fluvoxamine or paroxetine for 12 weeks. At 12 weeks, SSRI responders $(n=46)$ continued treatment with the SSRI and CBT was added, while SSRI-refractory patients $(n=44)$ were randomly assigned to receive augmentation with an SGA. Patients were initiated on risperidone ( $n=7$; mean dose $3.1 \pm 1.9 \mathrm{mg} /$ day $)$, quetiapine $(n=18$; mean dose $60.0 \pm 37.3 \mathrm{mg} / \mathrm{d})$ or olanzapine ( $n=18$; mean dose $5.1 \pm 3.2 \mathrm{mg} /$ day) for at least half a year in combination with CBT. At baseline of augmentation initiation, the SSRI plus atypical antipsychotic (SSRI-AAP) group had significantly higher mean total Y-BOCS score compared with responders $(29.3 \pm 9.9$ vs $25.8 \pm 11.4$, respectively; $p<0.01$ ), as well as significantly more obsessions, ordering, repeating rituals and hoarding symptoms (all $p<0.01$ ). At 1 year, the mean improvement rate in total Y-BOCS score in the responders group was significantly higher versus the SSRI-AAP group $(50.0 \pm 14.3$ vs $40.4 \pm 17.9$, respectively; $p<0.01$ ); however, there was no significant difference in the percentage of patients whose improvement rate was $>50 \%$. Increased body weight, increased appetite, mean BMI, and mean fasting blood glucose were all significantly more frequent in the SSRI-AAP group versus the responders after 1 year (all $p<0.01$ ). No patient discontinued treatment due to unwanted side effects. No significant differences were seen across individual antipsychotics in the mean reduction on Y-BOCS total score, follow-up mean BMI, fasting blood glucose, triglycerides, or total cholesterol levels. There was, however, a significantly higher difference seen in the mean rate of increased BMI with olanzapine and quetiapine compared with risperidone $(15.4 \pm 8.8$ and $13.8 \pm 9.4$ vs $6.5 \pm 4.4$, respectively; $p<0.01)$.

Several small studies $(n=6)$ have demonstrated mixed results with olanzapine used as augmentation to an SSRI in patients considered to have SSRI-refractory OCD. Of a 
total of 97 patients (48 male, 46 female, 3 unknown; mean age 36.1 years) who entered into each of these trials, $94 \%$ $(n=91)$ completed the desired length of each. The majority of trials analyzed olanzapine augmentation to an SSRI over 4-12 weeks, with the exception of one that looked at outcomes up to 1 year and one trial that included a patient that was augmented with venlafaxine. The most common SSRIs used within the trials included fluoxetine, fluvoxamine, and paroxetine augmented with titrated or fixed doses of olanzapine, with daily doses up to $5 \mathrm{mg}(n=2)$ and $10 \mathrm{mg}(n=4)$. The majority of patients were considered responders $(n=54)$ to olanzapine therapy versus nonresponders $(n=37)$. Response was defined within each trial but the majority used a decrease in Y-BOCS score, ranging from $>25 \%$ to $50 \%$, followed by a score of ' 2 ' or ' 1 ' on the CGI-I scale. Olanzapine was well tolerated with few patients stopping therapy due to unwanted side effects. The most commonly reported adverse events were sedation, weight gain, and increased appetite [69-74].

\subsubsection{Case Reports}

A total of 21 patients were observed through the literature by case reports and case series that demonstrated the use of olanzapine for treatment of OCD as both monotherapy $(n=2)$ and augmentation $(n=19)$. Overall, 76\% $(n=16)$ of patients experienced improvement in their OC symptoms, 9.5\% $(n=2)$ of patients worsened based on an increase in Y-BOCS score and one (5\%) patient's symptoms remained unchanged. In two patients (9.5\%), the Y-BOCS score was not reported [75-83]. The majority of patients were males (74\%; mean age 37 years) in the olanzapine as augmentation group. Patients received doses of olanzapine ranging from $1.25 \mathrm{mg} /$ day to $20 \mathrm{mg} /$ day over a period of 3 weeks -2 years. Sixteen patients (78\%) showed improvement on their Y-BOCS scores after initiation of olanzapine additional to an antidepressant $(n=15)$ or a mood stabilizer $(n=1)$ [75-80]. Two patients experienced worsened symptoms when olanzapine was added to fluvoxamine $200 \mathrm{mg}$ daily and paroxetine $40 \mathrm{mg}$ daily, while one patient experienced no change in symptoms $[79,83]$. Weight gain $(n=2)$ and sedation $(n=8)$ were the most commonly reported adverse events $[76,83]$. One patient discontinued treatment after 3 weeks due to sedation despite a decrease in Y-BOCS score [83].

Limited results were seen with patients who received olanzapine as monotherapy for treatment of OCD. Only two case reports were documented, with both stating improvements in OC symptoms with olanzapine monotherapy [81, 82]. Although both stated improvement, one patient did not have a documented Y-BOCS score [82]. The other patient experienced a decrease in his Y-BOCS score over 10 weeks from before olanzapine treatment (Y-BOCS 31) to after (Y-BOCS 16) [81].
The majority of the data analyzed proved olanzapine may be considered an option in treating patients with OCD. All trials presented and most of the case reports showed improvement in OCD symptoms when olanzapine was used in combination with an SSRI. Though limited in data, olanzapine also proved to have positive results in treating patients with OCD when used as monotherapy. The adverse event of weight gain may limit its use, as it was observed in each trial and case.

\subsection{Paliperidone}

\subsubsection{Evidence from a Randomized Controlled Trial}

One published study by Storch and colleagues is available on the use of paliperidone for OCD in adults. A doubleblind pilot study evaluating the efficacy and tolerability of paliperidone augmentation in 34 adults with treatmentresistant OCD who met DSM-IV criteria for OCD and were symptomatic following two or more adequate SRI trials. Patients were treated for 8 weeks with either paliperidone (up to $9 \mathrm{mg}$ per day) or matching placebo in addition to SRI. Use of paliperidone showed significant reductions in obsessive-compulsive symptoms based on Y-BOCS $(p<0.01)$. Placebo administration was associated with medium-sized, trend-level changes in Y-BOCS $(p=0.05)$. In exploratory analyses, paliperidone superiority compared with placebo was not significant $(p=0.14)$. Paliperidone was well tolerated and no significant weight gain was reported with its use [84].

Evidence of paliperidone in OCD is limited to one study, which suggests it may be beneficial in treatment-resistant patients.

\subsection{Quetiapine}

\subsubsection{Evidence from Randomized Controlled Trials}

The evidence in the use of quetiapine for the management of SRI-resistant OCD has been equivocal. Several randomized, placebo-controlled trials have failed to show significant difference for the quetiapine group [85-89]. In one randomized, placebo-controlled, comparison trial of clomipramine and quetiapine, Diniz and colleagues [85] randomized 54 patients who did not respond to fluoxetine monotherapy (at least 8 weeks) to fluoxetine + placebo, fluoxetine + clomipramine, or fluoxetine + quetiapine (maximum $200 \mathrm{mg} /$ day) groups. Baseline Y-BOCS score was 24.98 in the three treatment groups. The mean age of the patients was 33.78 (range 18-64) with mean duration of illness of 18.13 years. Nineteen (35\%) patients were comorbid with BDD, four patients with TTM, and 13 (24\%) with ExD. There were high rates of current mood episode (32 patients, 
$59 \%$ ) and anxiety disorders (42 patients, 78\%). Mean dose of fluoxetine was $72.96 \mathrm{mg} /$ day, while the mean for the clomipramine + fluoxetine group was $66.67 \mathrm{mg} /$ day due to pharmacokinetic interaction with clomipramine. Mean dose of quetiapine was $142 \mathrm{mg} /$ day, with sedation and drowsiness being the most intolerable adverse effect. After 12 weeks of blinded treatment, the final Y-BOCS score was 18 in the fluoxetine + placebo, 18 in the fluoxetine + clomipramine and 25 in the fluoxetine + quetiapine group $(p<0.001)$. The authors attributed quetiapine's failing to show difference to the frequent psychiatric comorbidities in the patients and the high placebo response rate [85]. It may also be that the duration of SSRI monotherapy treatment was not adequate and patients continued to respond to SSRI monotherapy beyond the screening phase.

Trials that differentiated quetiapine from placebo showed a wide range of therapeutic response [44, 90-93]. In a placebo-controlled, single-blind study by Atmaca and colleagues, 27 patients were deemed to have treatment-refractory OCD after 3 months of open-label screening phase of a single SRI therapy, and were randomized into quetiapine augmentation or placebo group. There was no significant difference between the groups with respect to current age, number of previous failed SRI treatment, or the baseline Y-BOCS score (23.9). Half of the patients had comorbid Axis I disorder (major depressive disorder, social phobia, hypochondriasis, and panic disorder). After 8 weeks of intervention, the mean Y-BOCS score decreased from 24.1 to 13.4 in the quetiapine group $(p<0.05)$, with non-significant change in the placebo group $(-2.4)$ [90]. In a head-to-head trial by Shoja Shafti and Kaviani [44], quetiapine was compared with aripiprazole in the management of fluvoxaminerefractory OCD, resulting in a clinically insignificant outcome (see Sect. 4.1.1).

\subsubsection{Case Reports}

Adjunctive use of quetiapine in treatment-resistant OCD has been described in three case reports (six patients). Five out of six patients had comorbid mood or anxiety disorder (age range 22-65 years, men and women). Two patients reported partial response to risperidone prior to a trial of quetiapine. Low-dose quetiapine (up to $200 \mathrm{mg} /$ day) was added to ongoing SRI as augmentation. In all cases, the final Y-BOCS scores were at or below 16 [94-96].

Quetiapine has shown mixed outcomes in treatment of SRI-resistant OCD. The controlled trials that assessed quetiapine had limitations, which makes it difficult to conclude the true benefit of quetiapine as an augmenting agent for treatment-resistant OCD. All the published case reports had positive outcomes from quetiapine, which suggest a possible benefit of quetiapine, though not conclusive.

\subsection{Risperidone}

\subsubsection{Evidence from Randomized Controlled Trials}

Studies of exposure and response prevention (EX/RP) compared with risperidone generally show superiority of EX/ RP. A trial of 100 patients on therapeutic SRI dose with at least moderate OCD severity was conducted in which patients were randomized to 8 weeks of EX/RP, risperidone, or placebo. Patients who responded entered a 6-month maintenance phase continuing the augmentation strategy received acutely. According to intent-to-treat analyses, EX/ RP demonstrated superior OCD outcomes compared with risperidone following the 6-month maintenance treatment based on the Y-BOCS (10.95 vs $18.70 ; p=0.009)$. A greater percentage of patients in the EX/RP group met response criteria (Y-BOCS decrease $\geq 25 \%$ : 70 vs $20 \% ; p<0.001$ ) and achieved minimal symptoms (Y-BOCS $\leq 12: 50$ vs $5 \%$; $p<0.001)$. The authors concluded that OCD patients taking SRIs who responded to EX/RP or risperidone during the acute phase maintained their improvement over the 6-month maintenance phase and EX/RP demonstrated superior outcomes after the 6-month maintenance phase [97]. Simpson and colleagues conducted a randomized clinical trial to compare two SRI augmentation strategies with placebo in adult patients with OCD. Patients included in this study had at least moderate OCD despite therapeutic SRI dose for at least 12 weeks before study entry. One hundred patients were randomized and 86 completed the trial. Patients were randomized to 8 weeks of risperidone $4 \mathrm{mg}$ daily, EX/RP, or pill placebo in addition to SRI therapy. Patients in the EX/RP group had significantly greater reduction in Y-BOCS scores by week 8 (EX/RP vs risperidone: mean [SE] - 9.72 [1.38]; $p<0.001$ and EX/RP vs placebo: mean [SE] - 10.10 [1.68]; $p<0.001)$. A greater percentage of patients receiving EX/ $\mathrm{RP}$ responded (Y-BOCS score decrease $\geq 25 \%$ ) compared with risperidone and placebo (80 vs $23 \%$ vs $15 \%$, respectively; $p<0.001$ ) and achieved minimal symptoms (Y-BOCS score $\leq 12 ; 43$ vs 13 vs $5 \%$, respectively; $p=0.001$ ). The authors concluded that adding EX/RP was superior to risperidone and placebo as augmentation in OCD patients receiving SRIs [98]. Wheaton and colleagues examined moderators and predictors of these augmentation strategies in a separate analysis. Patients who were on a stable SRI dosage were randomized to EX/RP, risperidone, or placebo. Significant moderators were pretreatment OCD severity, age, and depression. SRI augmentation with EX/RP was more effective than risperidone, and EX/RP superiority increased with baseline OCD severity and younger age [99].

Hegde and colleagues evaluated 92 patients with OCD who were initiated on risperidone augmentation without CBT and who had been receiving stable and adequate doses of SRIs for at least 12 weeks. Twenty-five percent of patients 
continued risperidone at the time of last follow-up and the remainder of patients discontinued risperidone due to intolerability or ineffectiveness. Patients who continued to take risperidone had significantly greater decrease in Y-BOCS scores compared with patients who did not continue (41.6 vs $3.7 \%$; $p<0.001$ ). Twenty-four percent of patients experienced a reduction of at least $25 \%$ in Y-BOCS score [100]. In a double-blind, placebo-controlled trial of risperidone augmentation to SRI therapy in adult, treatment-resistant OCD patients, patients who failed at least two SRI trials received either risperidone $0.5-3 \mathrm{mg}$ daily or placebo for 8 weeks following 12 weeks of SRI treatment. This study included 16 patients. Four patients of ten on risperidone, compared with none in the placebo group, responded with CGI-I score 1 or 2 and a Y-BOCS score decrease $\geq 25 \%$ [101]. In another double-blind, placebo-controlled study, McDougle and colleagues evaluated risperidone addition in patients with OCD refractory to SRI treatment. Thirty-six patients were randomized to risperidone or placebo for 6 weeks. Fifty percent of risperidone-treated patients responded compared with no patients in the placebo group $(p<0.005)$. Risperidone was significantly superior to placebo in decreasing OCD, depressive, and anxiety symptoms. Risperidone was well tolerated [102]. A double-blind, placebo-controlled study of lowdose risperidone augmentation of fluvoxamine treatment in OCD patients was conducted by Erzegovesi and colleagues. Forty-five patients were included and 39 patients completed the study. Five patients (50\%) receiving risperidone were responders compared with two (20\%) in the placebo group according to Y-BOCS scale reduction by $\geq 35 \%$. Risperidone was generally well tolerated [103]. In an open label study of 20 refractory OCD patients, risperidone was added and titrated to mean dose of $3 \mathrm{mg}$ daily over 8 weeks. All patients had a reduction in OCD symptoms according to decreased Y-BOCS total score. Risperidone was well tolerated [104]. Saxena and colleagues evaluated 21 SRI-refractory OCD patients who received adjunctive risperidone (mean dose $2.75 \mathrm{mg}$ daily). Five patients experienced akathisia and discontinued treatment. Sixteen patients continued combined treatment and 14 experienced significant reductions in OCD symptoms within 3 weeks [105].

Risperidone augmentation has been compared with other antipsychotic drugs as well. In a single-blind, randomized study, risperidone was compared with aripiprazole (see Sect. 4.1.1) [43]. A double-blind, placebo-controlled, crossover study comparing 2 -week adjunctive treatment with risperidone, haloperidol, and placebo in patients with OCD with severe symptoms on a stable dose of SRI was conducted by $\mathrm{Li}$ and colleagues. Sixteen patients were enrolled but 12 completed the study. Both risperidone and haloperidol significantly decreased obsession according to the Y-BOCS $(p<0.05)$. A decrease in the Hopkins Symptom Checklist 90-revised (SCL-90R) anxiety scale score was also observed. Risperidone improved depressed mood according to the Hamilton Rating Scale for Depression (HAM-D), the SCL-90R depression scale, and the Profile of Mood States. Five of 12 patients discontinued haloperidol treatment early due to adverse effects. All patients in the risperidone group completed the 2-week treatment [106]. Maina and colleagues conducted an 8-week, single-blind, randomized trial comparing risperidone (1-3 mg daily) with olanzapine (2.5-10 mg daily) in addition to SRI treatment. Patients included in this study were those with OCD who did not demonstrate $\mathrm{a} \geq 35 \%$ decrease in Y-BOCS score after 16 weeks of SRI treatment. Of 50 patients randomized to risperidone or olanzapine, significant response was observed in both groups, but no difference between the two treatment groups was noted [67]. In another study, 44 OCD patients who failed to respond to SSRIs were randomized to receive olanzapine, quetiapine, or risperidone and were treated with an SSRI plus atypical antipsychotic in combination with CBT for 1 year. Atypical antipsychotic augmentation reduced Y-BOCS total scores in SSRI-refractory patients. Compared with SSRI responders, total Y-BOCS scores for patients who received atypical antipsychotics were initially higher (SSRI-refractory patients $29.3 \pm 9.9$ vs SSRI responders $25.8 \pm 11.4 ; p<0.01)$ and remained higher following 1 year of treatment $(19.3 \pm 6.8$ vs $13.7 \pm 4.6 ; p<0.01)$. Patients in the atypical antipsychotic group reported significantly more frequent increased appetite and increased body weight [68].

\subsubsection{Case Reports}

Several case reports on risperidone use in OCD patients have been published. McDougle and colleagues report on three OCD patients who were unimproved after a minimum of 12 weeks of fluvoxamine treatment. Risperidone $1 \mathrm{mg}$ daily was added to fluvoxamine therapy. All three patients demonstrated significant improvement in Y-BOCS following risperidone addition. Y-BOCS scores decreased by 65,56 and $43 \%$ for the three patients, respectively, within 4 weeks of risperidone treatment. Risperidone was well tolerated with mild to moderate sedation noted [107]. Yoshimura and colleagues reported three OCD patients who were successfully treated with the addition of low-dose risperidone $(0.5-1 \mathrm{mg} /$ day $)$ to fluvoxamine with improvement in OCD symptoms and no evidence of extrapyramidal symptoms or other adverse events [108]. The case of a 43-year-old male with OCD treated with clomipramine $200 \mathrm{mg}$ daily, who saw decrease in OCD symptoms and Y-BOCS score with addition of titrated risperidone therapy, is presented by Kawahara and colleagues [109]. Sun and colleagues reported two OCD patients who had poor response to fluoxetine and paroxetine. Neither patient received behavioral therapy or psychotherapy. Both patients demonstrated significant 
improvement in Y-BOCS scores after addition of risperidone $1 \mathrm{mg}$ daily to paroxetine therapy. Following 4 weeks of risperidone, Y-BOCS scores reduced by 57 and 53\% [110]. Ravizza and colleagues evaluated the short-term efficacy and safety of adjunctive risperidone in SSRI-refractory OCD patients. Fourteen patients who were SSRI nonresponders received risperidone augmentation and showed good clinical improvement and drug tolerability [111]. Stein and colleagues reviewed charts of patients treated in an OCD clinic with an SSRI and risperidone combination. Eight OCD patients were refractory to SSRI treatment and had received risperidone augmentation. Three OCD patients reported very much or much improvement in OCD symptoms, one patient minimal to much improvement, and one patient experienced intolerable side effects of increased anxiety and irritability [112]. Agid and Lerer present the case of a 25 -year-old White male with severe, treatmentrefractory OCD who responded with improved obsessive and compulsive symptoms to the addition of risperidone $0.5 \mathrm{mg}$ daily in addition to paroxetine treatment [113]. In contrast, a case report of a 21-year-old OCD patient with no comorbid disorders receiving fluoxetine therapy whose obsessive-compulsive symptoms rapidly worsened with the addition of risperidone titrated up to $3 \mathrm{mg}$ daily over 3 days has been reported. Following risperidone discontinuation, the patient gradually recovered over the course of 3 months; however, he did not attain pre-risperidone status [114].

Evidence reveals EX/RP is superior to risperidone, and risperidone augmentation is superior when compared with placebo. One study comparing aripiprazole to risperidone showed risperidone augmentation to be superior. When compared with haloperidol or olanzapine, both risperidone and comparator drug decreased OCD symptoms but no difference was seen between the two groups. One study comparing olanzapine, quetiapine, and risperidone showed reduced Y-BOCS scores in all patients who received atypical antipsychotic augmentation. The majority of case reports and series describe improved OCD symptoms with the addition of risperidone.

\subsection{Ziprasidone}

\subsubsection{Evidence from Uncontrolled Trials}

Published data on ziprasidone for OCD are limited. Bruno and colleagues performed a 12-week, open-label, uncontrolled trial on ziprasidone as add-on therapy in patients with treatment-resistant OCD being treated with SRIs. In 17 patients studied, add-on ziprasidone moderately but significantly reduced compulsive symptoms based on the Y-BOCS score. No patient experienced a full response defined as $\geq 35 \%$ reduction in Y-BOCS score [115]. Savas and colleagues conducted a retrospective evaluation of 24 treatment-resistant OCD patients followed for 24 weeks. Patients had OCD without psychotic features according to DSM-IV criteria. Fifteen patients were prescribed quetiapine $(100 \mathrm{mg} /$ day titrated up to maximum of $1200 \mathrm{mg} /$ day $)$ and nine patients were prescribed ziprasidone $(80 \mathrm{mg} /$ day titrated up to a maximum of $160 \mathrm{mg} /$ day) as adjunctive therapy to high dose SRIs. Patients who did not reach the 6-month follow up, had a history of severe physical illness, alcohol and substance abuse or dependence, comorbid psychiatric conditions, or who were treated with a combination of antidepressants, typical antipsychotics, atypical antipsychotics other than quetiapine and ziprasidone, or mood stabilizers were not included. Clinical improvement was defined as an improvement of $\geq 30 \%$ on the Y-BOCS score 2 months after the initial diagnosis. Clinical improvement was observed in $80 \%$ of quetiapine-treated patients and $44.4 \%$ of ziprasidonetreated patients $(p>0.05)$. The mean Y-BOCS scores for the ziprasidone group were significantly higher than the quetiapine group at 2-, 3-, and 6-month follow-up $(p<0.05)$. CGI-S scores were higher in the ziprasidone group at 2-, 3-, and 6-month follow-up $(p<0.05)$ [93].

Limited evidence with ziprasidone for OCD shows moderate improvement with the drug and that it was less effective than quetiapine in one study.

\subsection{Review of Available Meta-Analyses and Reviews for the Efficacy of SGAs for OCD}

Bloch and colleagues conducted a meta-analysis of nine double-blind, randomized, placebo-controlled trials of antipsychotics as augmentation treatment for treatment-refractory OCD ( $n=278 ; 3$ quetiapine, 3 risperidone, 2 olanzapine and 1 haloperidol). Based on response criteria of $35 \%$ reduction in Y-BOCS score, haloperidol and risperidone were deemed efficacious while the evidence for olanzapine and quetiapine was inconclusive. Overall, antipsychotic augmentation was efficacious in one third of the patients [116].

The subsequent meta-analysis of randomized controlled trials assessing efficacy of SGAs in treatment-resistant OCD was conducted by Skapinakis and colleagues. In this meta-analysis, ten trials were included (1 haloperidol, 3 risperidone, 2 olanzapine, 4 quetiapine). Criteria for successful treatment was the percent reduction in Y-BOCS set by respective investigators (35\% reduction in 5 trials and $25 \%$ in the other 5 trials). The authors concluded that antipsychotics were associated with a higher response rate than placebo, though a high level of heterogeneity among the trials was present. The heterogeneity was reduced when moderate-high dose was used and when the duration was $>8$ weeks. Treatment-associated adverse effects were not addressed [117].

Komossa and colleagues conducted a review of SGAs in OCD (11 trials, $n=396)$. Based on treatment response definition of at least $25 \%$ reduction in Y-BOCS score, 
risperidone was more efficacious than placebo in the primary outcome (25\% reduction in Y-BOCS score). While olanzapine had some efficacy-related outcomes, it was offset by strong risk of weight gain. Quetiapine was not any more efficacious than placebo [118]. Haloperidol was not included in the review because of its predictable risk of extrapyramidal adverse effects and because the single trial that was conducted with haloperidol was prior to most trials with atypical antipsychotics.

A report by the Agency for Healthcare Research and Quality on the efficacy of SGAs in off-label uses, including OCD, concluded that risperidone and quetiapine may have efficacy, but the adverse effects were common. Risperidone as augmentation of an SSRI had moderate-to-high evidence, while olanzapine as augmentation of an SSRI had low-to-very low evidence. Quetiapine showed low-to-very low evidence as augmentation of citalopram, but this was conflicted with moderate-to-high evidence of inefficacy as augmentation of an SSRI. There was no trial available for asenapine, iloperidone, and paliperidone [119].

Dold and colleagues conducted a review of double-blind, placebo-controlled, randomized trials of 14 studies that comprised of 491 participants with OCD resistant to SRI. The impact size was the greatest with quetiapine $(n=142)$, followed by risperidone $(n=132)$, aripiprazole $(n=79)$, olanzapine $(n=70)$, paliperidone $(n=34)$, and haloperidol $(n=34)$. Mean Y-BOCS score decrease was the primary outcome of the meta-analysis. Statistically significant superiority over placebo was noted in aripiprazole, haloperidol, and risperidone trials, while olanzapine, paliperidone, and quetiapine trials failed to differentiate from placebo. Response rate as defined by Y-BOCS decrease $\geq 35 \%$ was $30 \%$ overall (compared with $12.5 \%$ in placebo). There were overall significantly more adverse effects in the antipsychotic treatment group compared with placebo group, although the discontinuation rate did not differ between the groups [120]. Earlier meta-analysis led by the same author concluded that only risperidone had significant benefit based on absolute Y-BOCS score reduction and a 35\% decrease cut-off in Y-BOCS score as response. Aripiprazole and haloperidol were then each supported by a single trial and, thus, were not classified as having strong evidence [121].

According to a systematic review and meta-analysis by Maher and colleagues, the overall evidence of SGAs in the treatment of OCD in patients who were resistant to an SSRI was deemed moderate. Ten placebo-controlled trials with olanzapine, quetiapine, aripiprazole, and risperidone were reviewed against treatment response criteria of change in Y-BOCS score. Two trials with olanzapine did not show significant improvement compared with placebo, and five trials with quetiapine only showed a trend toward improvement with antipsychotic treatment, with no statistical significance. While the three trials with risperidone showed superior outcome with the antipsychotic, the potential for publication bias was present [122].

Veale and colleagues published a meta-analysis of 14 placebo-controlled, randomized clinical trials of SGAs in SRI-resistant OCD $(n=493)$ [123]. The authors sought to identify the appropriate place of therapy as part of stepped care for patients with SRI-resistant OCD according to UK treatment guidelines. Included trials had one of the following SGAs: risperidone (4 trials), olanzapine (2 trials), quetiapine (5 trials), paliperidone (1 trial) and aripiprazole ( 2 trials). Efficacy was defined as change in Y-BOCS score after antipsychotic augmentation. Statistically significant superiority was seen only in risperidone and aripiprazole trials. The authors did not report overall adverse effects across the included trials [124].

\subsection{Summary Statement for OCD}

Based on the review of data, aripiprazole and risperidone may have the most benefit as an augmentation strategy to SRIs in patients with SRI-resistant OCD. Evidence remains inconclusive for quetiapine, while severe metabolic adverse events limit olanzapine use, though the evidence is greater than for quetiapine. Paliperidone seems promising, given that it is a metabolite of risperidone. Table 2 summarizes high-evidence clinical trials in OCD.

\section{Body Dysmorphic Disorder (BDD)}

\subsection{Aripiprazole}

\subsubsection{Case Report}

Uzun and Ozdemir described a patient who had a partial response to fluvoxamine $400 \mathrm{mg} / \mathrm{day}$ for BDD and received adjunctive aripiprazole $10 \mathrm{mg}$ /day to have substantial reduction in time spent on thinking about bodily defect [125]. The patient's response was measured using Body Dysmorphic Disorder Exam (BDDE), an instrument that was developed after the development of BDD-Y-BOCS with enhanced measurement of symptoms of severely negative body image [7]. Her BDDE score was 92 after 6 months of maximum-dose fluvoxamine therapy $(400 \mathrm{mg} /$ day), which represented $<20 \%$ decrease in BDDE scores. Aripiprazole augmentation was initiated at this point and was maintained for 10 weeks. Her BDDE score at the end of 10 weeks was 42 . No significant adverse effect was reported. 


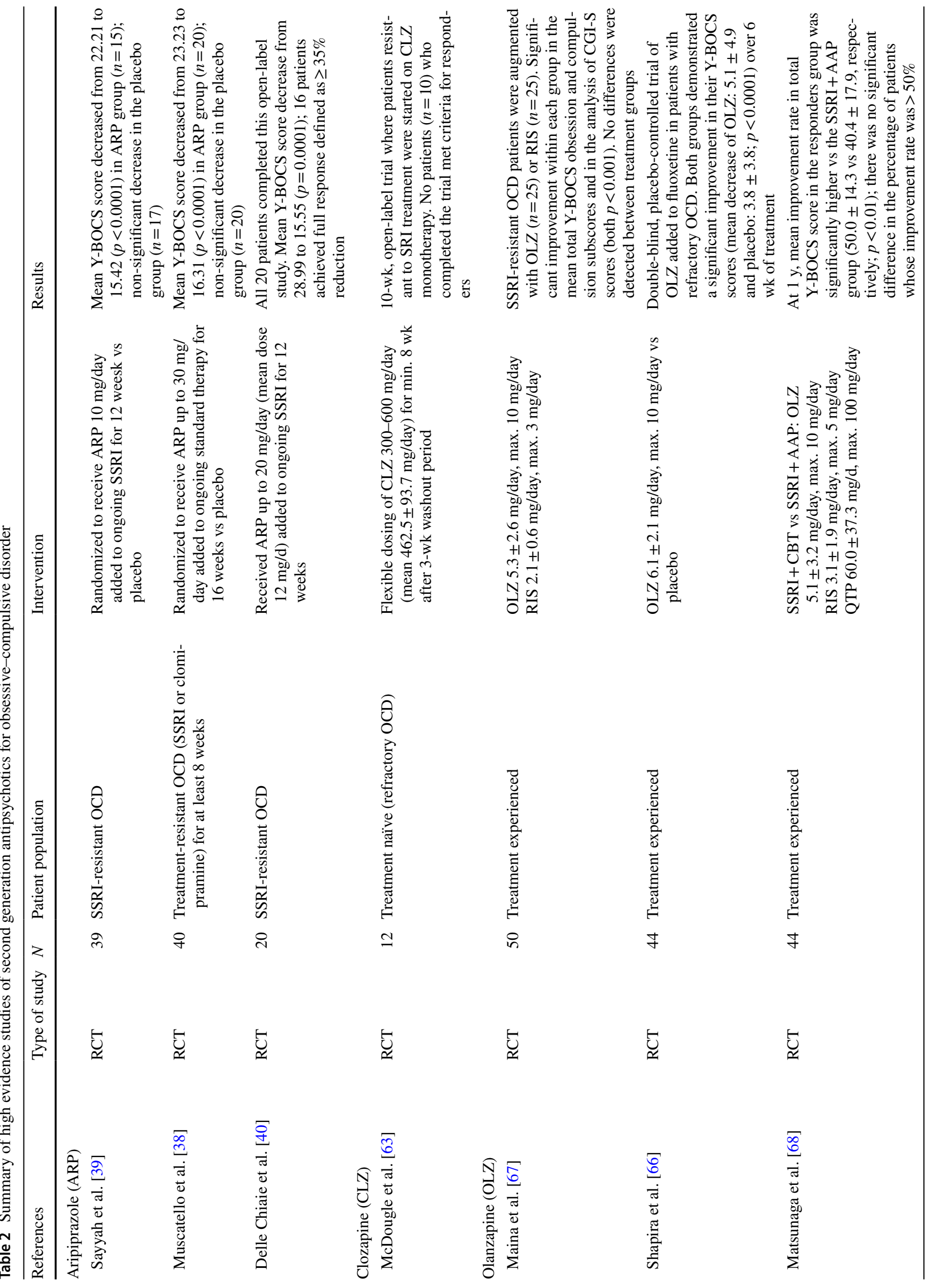




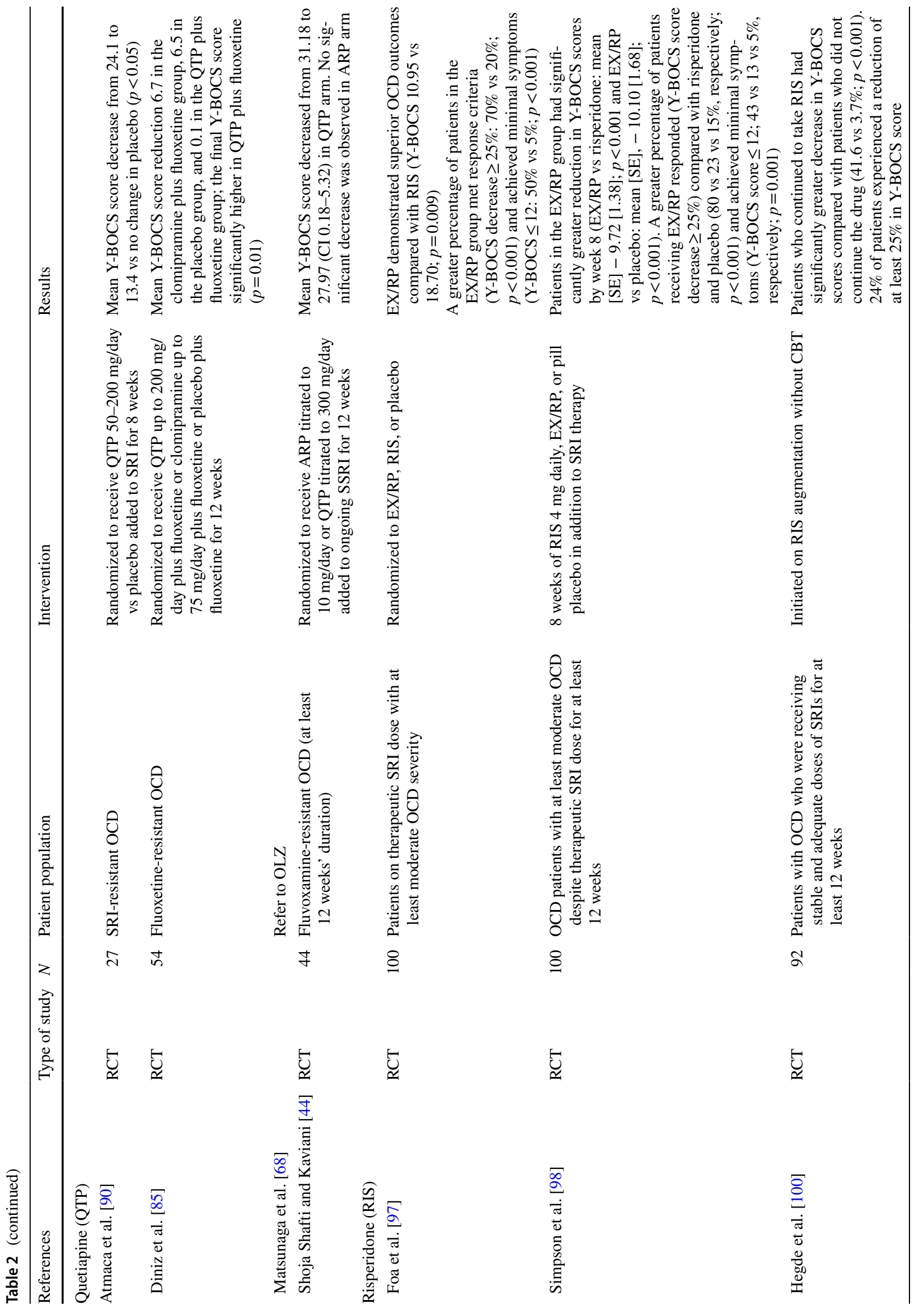




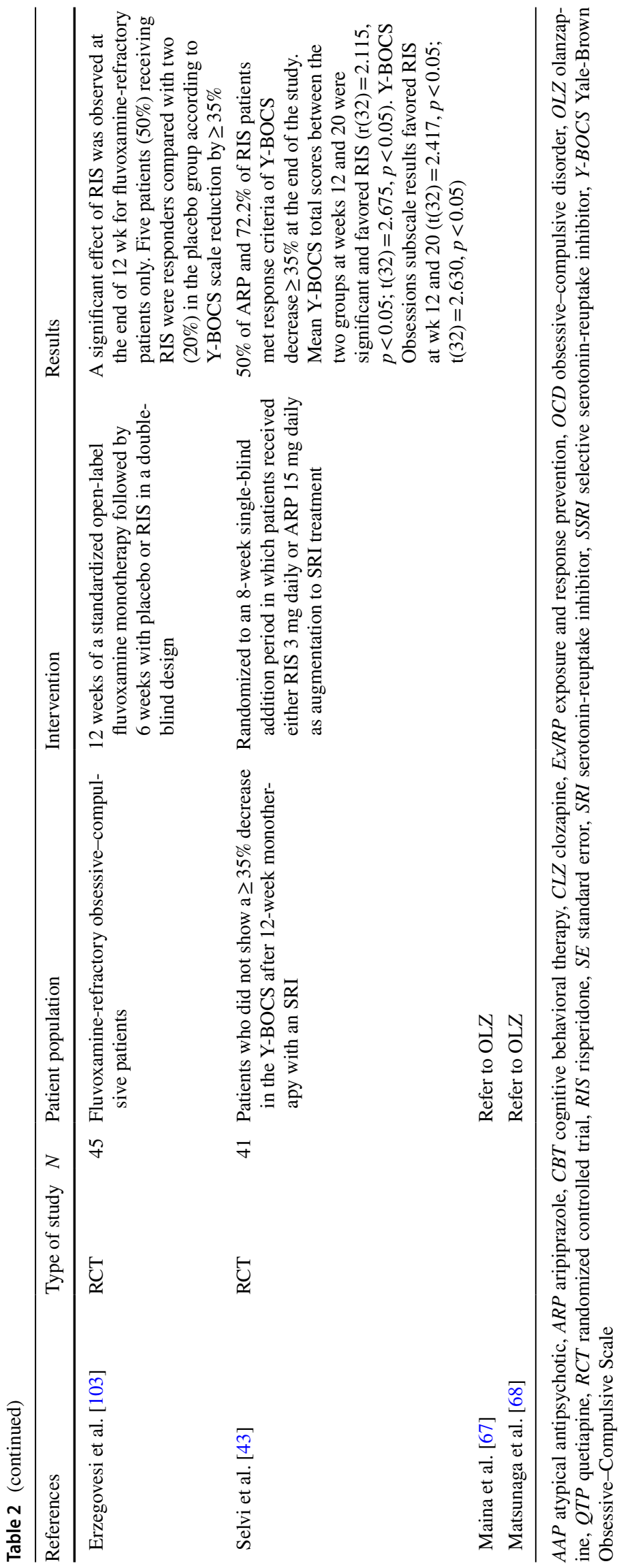


One case report suggests possible benefit of aripiprazole in SRI-refractory BDD.

\subsection{Olanzapine}

\subsubsection{Evidence from an Uncontrolled Trial}

Phillips demonstrated olanzapine augmentation of fluoxetine in patients diagnosed with BDD. Six patients (mean age 29.3 years) were treated with fluoxetine (mean dose $70 \pm 11 \mathrm{mg} /$ day) tapered and maintained for $\geq 12$ weeks. If patient's response to the fluoxetine was deemed inadequate, olanzapine $2.5 \mathrm{mg}$ daily was added to therapy and titrated to a goal of $15 \mathrm{mg} /$ day over 8 weeks. Inadequate response was defined as still meeting criteria for BDD, BBD score $\geq 20$ on the Y-BOCS modified for BDD scale, and were no more than minimally improved on the CGI scale. Over an average duration of $5.3 \pm 3.1$ weeks, two patients experienced minimally improved BDD symptoms on the CGI scale and four patients remained unchanged with a mean daily dose of olanzapine $4.6 \pm 3.3 \mathrm{mg}$. Adverse effects of fatigue $(n=2)$ and weight gain $(n=3)$ were reported [126].

\subsubsection{Case reports}

Two case reports demonstrated efficacy of olanzapine in the treatment of BDD [127, 128]. The first case illustrated a 26-year-old woman who was diagnosed with BDD and responded to combination treatment with paroxetine $40 \mathrm{mg}$ per day augmented with olanzapine $5 \mathrm{mg}$ per day. The patient's preoccupations with appearance began to subside and her Y-BOCS score decreased from 39 to 20 after 6 weeks. Her symptoms were still resolved at a 1-year followup, though she did complain of undesired weight gain [127]. The second case demonstrated a 46-year-old woman who was diagnosed with BDD due to preoccupations with her hair, alcohol dependence, and bipolar II disorder. After a failed 1-year trial of fluoxetine $80 \mathrm{mg}$ daily, she was started on monotherapy with olanzapine $5 \mathrm{mg}$ and titrated up to $20 \mathrm{mg}$ daily over 2 weeks. After 3 weeks, she reported no preoccupation with her appearance and no longer met criteria for BDD; her symptoms were still resolved after 8 weeks [128].

Current evidence demonstrates conflicting evidence on the use of olanzapine as monotherapy or adjunct therapy in BDD.

\subsection{Quetiapine}

\subsubsection{Evidence from a Randomized Controlled Trial}

Diniz and colleagues conducted a prospective, randomized trial of sequential treatment for OCD comorbid with BDD. After receiving fluoxetine $80 \mathrm{mg} /$ day for 12 weeks, patients with suboptimal response were randomized into fluoxetine plus clomipramine, fluoxetine plus quetiapine, or fluoxetine plus placebo for 12 weeks. The patients were more likely to remain non-responders if they had BDD comorbidity $(p=0.036)$. The trial was not designed to test efficacy of quetiapine in the treatment of BDD; therefore, it remains unknown whether quetiapine benefits patients with SRI-refractory BDD [129].

\subsection{Risperidone}

\subsubsection{Case report}

One case report of risperidone use for BDD is available. Goulia and colleagues report a 26-year-old male diagnosed with BDD and delusional disorder somatic type who was initially administered pimozide then switched to risperidone $2 \mathrm{mg}$ daily, gradually increasing to $4 \mathrm{mg}$ daily. Venlafaxine $37.5 \mathrm{mg}$ daily was added and then increased to $150 \mathrm{mg}$ daily due to deteriorating mood. No adverse effects were reported and the patient was free of symptoms in 6 months [130].

Risperidone may have benefited a patient with BDD and delusional disorder somatic type who also received venlafaxine.

\subsection{Summary statement for BDD}

Based on the review, there is no strong evidence that any SGA benefits patients with SRI-refractory BDD. A small number of case reports with positive outcomes have been published with aripiprazole and risperidone. The weight gain potential of olanzapine may actually worsen the disease burden.

\section{Hoarding Disorder (HD)}

\subsection{Quetiapine}

\subsubsection{Case report}

The only case report of the use of quetiapine for the management of HD was in a medication-naïve patient with HD. A 52-year-old married man was treated with fluvoxamine $300 \mathrm{mg} /$ day plus quetiapine $200 \mathrm{mg} /$ day, and was noted to have improvement in symptoms. This effect was present as far as 9-month follow-up [131]. Since the patient was not diagnosed with treatment-refractory HD, the benefit of quetiapine in such patients remains unknown.

\subsection{Risperidone}

\subsubsection{Case Reports}

Reports of risperidone for HD are limited to two case reports. A 56-year-old male with compulsive hoarding, 
attention deficit/hyperactivity disorder, and schizotypal personality disorder benefited from a regimen of fluvoxamine, amphetamine salts, and risperidone, in addition to behavioral therapy. The patient's hoarding behaviors, motivation, procrastination, and socialization all improved with this treatment regimen [132]. Chong and colleagues reported a 36-year-old Chinese female with schizophrenia and hoarding. The patient showed no improvement of psychosis or hoarding after 14 weeks of maximum-dose clozapine or when an SSRI was added. The SSRI was discontinued and clozapine dose reduced to $200 \mathrm{mg}$ daily. Risperidone $1 \mathrm{mg}$ daily was added and titrated up to $6 \mathrm{mg}$ daily for 16 weeks. A worsening of hoarding symptoms was observed. The intensity of her hoarding decreased following risperidone discontinuation. Psychotic symptoms showed no improvement [133].

Two case reports of risperidone for hoarding disorder demonstrate benefit in one and worsening of symptoms in the other; however, both patients had comorbid psychiatric conditions.

\subsection{Summary Statement for HD}

Currently, there is no evidence to suggest that any SGA benefits patients with treatment-refractory HD. Though serotonergic agents are suggested as an initial treatment option, well designed trials are lacking to support this approach.

\section{Trichotillomania (TTM)}

\subsection{Aripiprazole}

\subsubsection{Evidence from an Uncontrolled Trial}

White and Koran conducted an 8-week, open-label study with flexible-dosing aripiprazole (dose range 3-15 mg) for the management of TTM. Twelve female patients were enrolled in the study, eight patients with documented treatment failure to serotonergic agents. The reduction of the hair pulling was seen as early as 2 weeks and was sustained through the end of 8 weeks. The primary outcome using MGHHPS showed significant reduction in MGHHPS (mean change $-7.8 ; p \leq 0.01)$ [134].

\subsubsection{Case Reports}

Four case reports have been published for aripiprazole in the management of TTM. Howard and colleagues reported a case of a patient who had Huntington's disease and comorbid TTM, in whom aripiprazole was titrated to $5 \mathrm{mg}$ /day, resulting in full remission of TTM by 18 months. The patient was noted to have gained $30 \mathrm{~kg}$ (66 lbs) over the course of therapy [135]. Virit and colleagues describe a 39-year-old woman with TTM comorbid with restless legs syndrome. Aripiprazole $5 \mathrm{mg}$ /day was added to her ongoing venlafaxine $150 \mathrm{mg} /$ day and clonazepam $2 \mathrm{mg} /$ day as an attempt to manage restless leg syndrome. However, the patient noted clinical improvement in TTM and restless leg syndrome after 6 weeks. When she stopped taking aripiprazole, TTM symptoms came back in 3 months [136]. Another case report by Jefferys and Burrows described a 32-year-old woman with SRI-resistant TTM. Aripiprazole was titrated to $15 \mathrm{mg} /$ day and resulted in full remission as a monotherapy [137]. Lowdose aripiprazole $(1.5-3 \mathrm{mg} /$ day $)$ as an augmenting agent successfully remitted TTM in a paroxetine-resistant patient with TTM [138].

One open-label study along with four positive case reports suggest aripiprazole's potential benefit in patients with treatment-refractory TTM.

\subsection{Olanzapine}

\subsubsection{Evidence from Randomized Controlled Trial}

A randomized, double-blind, placebo-controlled trial looked at the effectiveness of olanzapine as monotherapy for the treatment of TTM. Adult patients $(n=25$; mean age 33.2 years) were randomized to receive a flexible dose of olanzapine (2.5-20 mg/day) or placebo for 12 weeks. Olanzapine showed a significant change in mean scores from baseline to endpoint versus placebo on the CGI-I (3.38-1.69 vs 3.41-3.41, respectively; $p=0.001)$, CGI-S (5.08-3.15 vs 5.00-4.83, respectively; $p<0.001$ ), and TTM-Y-BOCS scores (20.70-10.54 vs 20.67-18.17, respectively; $p<0.01$ ). Conversely, olanzapine did not show a significant difference in MGH scores versus placebo (15.46-8.38 vs $16.58-13.25$, respectively; $p=0.30$ ). The mean time to treatment response with olanzapine was reported as 8.2 weeks with a mean study dose of $10.8 \mathrm{mg} /$ day at endpoint. There was a significant difference in the mean number of adverse events reported with olanzapine versus placebo (4.2 vs 1.3 , respectively; $p<0.001$ ), as well as a significant increase in reported adverse events with daily doses of $10 \mathrm{mg}$ of olanzapine versus 5 and $20 \mathrm{mg}(5.5 \pm 1.0$ vs $3.0 \pm 1.8$ vs $3.0 \pm 1.4$, respectively; $p<0.001$ ) [139].

\subsubsection{Evidence from an Uncontrolled Trial}

Stewart and Nejtek suggested the effectiveness of olanzapine in a 3-month, open-label, flexible-dose study. The study looked at changes in hair pulling, measured by MGHHPS, Hamilton Rating Scale for Anxiety (HAM-A), HAM-D and CGI scales, in patients who met DSM-IV criteria for TTM with no other comorbid psychiatric disorders. Patients were excluded if they were being treated with any other 
psychoactive medication. Patients $(n=17$; mean age 36.8$)$ were titrated gradually on olanzapine in $2.5-\mathrm{mg} /$ week intervals (max dose $10 \mathrm{mg} /$ day). Patients were assessed at baseline and weeks 1, 2, 4, 6, 8, and 12. Statistically significant changes in MGH $(p \leq 0.01)$, HAM-A $(p \leq 0.01)$, HAM-D $(p \leq 0.01)$, and CGI $(p \leq 0.001)$ scores from baseline were seen at 6 weeks (mean dose $6.0 \mathrm{mg} /$ day). Analysis showed that hair pulling decreased significantly from baseline to endpoint by $66 \%$, as well as a significant $50 \%$ improvement in CGI scores (both $p \leq 0.001$ ). The most commonly reported adverse effects were sedation and weight gain [140].

\subsubsection{Case Reports}

Gupta and Gupta described a 30-year-old female diagnosed with TTM at the age of 13 who experienced significant improvement in her hair-pulling symptoms with olanzapine as monotherapy (dose $5 \mathrm{mg}$ daily) titrated over a 4-week timeframe. She maintained being symptom-free for 6 months with no reports of adverse effects [141]. Several other cases $(n=6)$ have reported mixed evidence for the use of olanzapine as augmentation in the treatment of TTM in adults. The majority of these patients were female (84\%) between the ages of 18-49 years who had a previously failed trial of medication for their TTM symptoms. All positive data reported treatment with olanzapine augmented to an SSRI, specifically fluoxetine $(n=2)$ and citalopram $(n=3)$ [142-144]. One patient did experience a significant decrease in hair pulling with a combination of risperidone $1 \mathrm{mg}$ per day and fluvoxamine $300 \mathrm{mg}$ per day; however, she was unable to tolerate this regimen due to galactorrhea and was therefore switched to a combination of fluoxetine and olanzapine, where she reported undesired weight gain [143]. No other patients reported any adverse effects with olanzapine. One of the six patients treated with carbamazepine augmented with olanzapine did not experience improvement in her TTM symptoms with the addition of olanzapine [144].

Two trials and one case report demonstrated positive results for the use of olanzapine as monotherapy for the treatment of TTM. In addition, the majority of the case reports analyzed suggest that olanzapine is effective in treating TTM in combination with an SSRI, specifically fluoxetine and citalopram.

\subsection{Quetiapine}

\subsubsection{Case Reports}

A 20-year-old female patient with TTM receiving fluoxetine $40 \mathrm{mg} /$ day was initiated on quetiapine (titrated to $100 \mathrm{mg} /$ day). In 2 weeks, her symptoms remitted and did not return in 4 months [145]. Jones and colleagues reported a case of a 37-year-old female patient presenting with TTM/ trichophagia. The patient reported less urge to consume hair and showed other favorable clinical signs with quetiapine (100 mg/day) [146]. Khouzam et al. also described a positive clinical response of a 33-year-old female veteran with TTM to quetiapine [147].

Low-dose quetiapine has been described in three case reports, suggesting possible benefit in reduction of hair pulling in TTM.

\subsection{Risperidone}

\subsubsection{Case Reports}

Data on risperidone to treat trichotillomania is limited to a few case reports. Senturk and Tanriverdi reported a 22-yearold, treatment-resistant trichotillomania patient with previous unsuccessful treatment with clomipramine, venlafaxine, pimozide, fluoxetine, and cognitive behavior psychotherapy treated with risperidone $2 \mathrm{mg} /$ day (increased to $8 \mathrm{mg}$ /day after 4 weeks). Following risperidone initiation, the patient reported feeling more emotionally stable, her sleeping habits normalized, and hair pulling stopped. When risperidone was discontinued, trichotillomania symptoms reappeared. When risperidone was reinitiated, the patient's symptoms stopped [148]. A 27-year-old woman with trichotillomania and bulimic symptoms who was treated with paroxetine $60 \mathrm{mg}$ daily for 2 years with no effective reduction in trichotillomania symptoms was gradually transitioned from paroxetine to fluvoxamine (increased to $250 \mathrm{mg} /$ day). During the first 6 weeks of treatment with fluvoxamine, her hair pulling and bulimic symptoms worsened with manifestation of angry, frustrated mood and suicidal ideation. Risperidone $0.5 \mathrm{mg}$ in the morning and $1 \mathrm{mg}$ at night was added to fluvoxamine $250 \mathrm{mg}$ /day. Within 1 week of risperidone initiation, symptoms decreased. Within 6-8 months, her eyelashes grew to normal length and she resumed her occupation. When risperidone was discontinued and fluvoxamine dose was reduced, symptoms re-emerged [149]. Oravecz et al. report the case of an 85-year-old female with major depressive disorder and Alzheimer's disease treated with sertraline $25 \mathrm{mg}$ and memantine $20 \mathrm{mg}$ daily. She was diagnosed with trichotillomania and treated with risperidone $0.5 \mathrm{mg}$ daily and naltrexone $25 \mathrm{mg}$ daily, increased to $50 \mathrm{mg}$ daily after 14 days. The patient experienced complete decrease of trichotillomania symptoms after 2 weeks of treatment and no adverse effects were observed [150]. Epperson and colleagues describe three cases of SRI-refractory trichotillomania. Patients received risperidone $0.5-3 \mathrm{mg}$ daily. All three patients experienced decreased hair pulling according to clinician-rated instruments [151].

Based on several case reports, risperidone seems promising for patients with trichotillomania. 


\subsection{Summary Statement for TTM}

Positive case reports are available for aripiprazole, quetiapine, olanzapine and risperidone, and this indicates their potential benefit in patients with TTM. The doses used were typically low across the agents. Controlled trial exists for olanzapine, but because olanzapine did not differentiate on the MGHHPS, it remains unknown if olanzapine's benefit outweighs the risk of severe metabolic adverse effects.

\section{Excoriation (ExD)}

\subsection{Aripiprazole}

\subsubsection{Case Reports}

Three case reports have been published. In a report by Curtis and Richards, an 18-year-old female with SSRI-resistant ExD and comorbid OCD experienced resolution of skin picking after aripiprazole $2.5 \mathrm{mg}$ was added daily to ongoing fluoxetine $100 \mathrm{mg}$. Her OCD symptoms decreased by $30-40 \%$ when aripiprazole was titrated to $5 \mathrm{mg}$ daily [50]. In another case report, a 50-year-old female with excoriation with comorbid major depressive disorder and generalized anxiety disorder was successfully treated with aripiprazole $10 \mathrm{mg}$ in addition to ongoing venlafaxine $225 \mathrm{mg} /$ day. The patient experienced a 16-lb weight gain as an adverse effect of aripiprazole [152]. Turner and colleagues described a 21-year-old female who was seen for skin picking during hospitalization for a small bowel transplant. After minimally responding to quetiapine and mirtazapine, aripiprazole was initiated at $10 \mathrm{mg}$ daily. The benefit on skin picking was seen as early as $48 \mathrm{~h}$ after initiation and continued until the end of 3-week follow-up [153].

Several case reports suggest possible benefit of aripiprazole in treatment-experienced $\mathrm{ExD}$, though evidence from controlled trials is lacking.

\subsection{Olanzapine}

\subsubsection{Case Reports}

Little evidence exists for olanzapine in the treatment of ExD. Our search revealed one case report, a case series, and a review article that all describe positive results with olanzapine as monotherapy and as adjunctive therapy for the treatment of excoriation [154-156]. In both case reports, a total of six patients, aged 29-64 years (mean 50 years), received olanzapine as monotherapy $(n=3)$ and as augmentation $(n=3)$ in doses that ranged from 5 to $10 \mathrm{mg}$ daily (mean $6.25 \mathrm{mg})$. The majority of patients were female $(83 \% ; n=5)$ and all patients experienced improvement within $2-4$ weeks of treatment. Three patients were treated in conjunction with an SSRI, specifically sertraline $(n=1)$, fluoxetine $(n=1)$, and paroxetine $(n=1)$. No adverse events to therapy were reported in any patient $[154,155]$.

\subsection{Summary Statement for ExD}

No controlled trial has been published on the use of any SGA in treatment-refractory ExD. Case reports of the use of aripiprazole and olanzapine in treatment-experienced ExD, particularly SRI, suggest possible benefit.

\section{Ongoing Clinical Trials}

Eleven clinical trials involving any SGA in OCD are listed in the US National Library of Medicine Clinical Trials Registry at the time of writing ( 10 completed, 1 not yet recruiting). They involve aripiprazole ( 2 trials), quetiapine (4 trials), olanzapine ( 2 trials), risperidone (1 trial), ziprasidone ( 1 trial), and paliperidone (1 trial). Three trials compared the SGA with behavioral therapy, three trials with clomipramine. There are two trials assessing the efficacy of olanzapine and aripiprazole in patients with trichotillomania (both completed) (www.clinicaltrials.gov).

\section{Discussion and Future Direction}

Due to SGAs' inherently heterogeneous nature in their receptor-binding characteristics, it is difficult to expect any classwide efficacy or lack thereof surrounding the use of SGAs in OCRD. When reviewing the literature for evidence, selective reporting and selective publication must be taken into consideration [157]. The number of serious metabolic adverse effects of SGAs have been well documented and must be considered against the small amount of evidence found in literature [158]. Nonetheless, based on the published trials (controlled and uncontrolled) and reports, aripiprazole and risperidone seem to have the strongest evidence across the treatment-refractory OCRDs, with exception of HD. Olanzapine's potential benefit is offset by weight gain in OCD and BDD, though not reported likewise in TTM and ExD. Quetiapine produced equivocal results in several controlled trials in OCD, but has promising case reports in TTM. Paliperidone is a metabolite of risperidone and has promising data based on one controlled study in OCD.

The positive findings from these case reports and clinical trials may lay the foundation for yet another serendipitous discovery of the efficacy of antipsychotics in non-psychotic diseases [159]. Time will tell whether SGAs as a class, or any number of individual agents, will become widely adopted as a treatment for one or more OCRDs. As the use 
of SGAs is being explored beyond schizophrenia, bipolar disorder, and treatment-resistant depression, the decision to use SGAs for the treatment of OCRD should be made cautiously. More research is direly needed in the cause and the pathophysiology of OCRD, specifically the diseased neurotransmitter system(s) and the circuitry, in order to align the pharmacodynamic properties of the SGAs for treatment.

\section{Limitations}

The major limitation in this review is the lack of controlled trials in the use of SGAs in treatment-resistant OCRDs. Particularly, controlled trials, which yield the strongest evidence, are lacking in the use of SGAs in BDD, HD, TTM, and ExD. Case reports and series only suggest potential benefit and are more prone to publication bias. It is important that well designed trials are conducted to assess the true efficacy of SGAs in BDD, HD, TTM, and ExD.

\section{Compliance with Ethical Standards}

Funding No funding was used to assist with the preparation of this review.

Conflicts of interest The following authors state there is no conflict of interest: Dongmi Kim, Nicole L. Ryba, Julie Kalabalik, and Ligia Westrich.

Open Access This article is distributed under the terms of the Creative Commons Attribution-NonCommercial 4.0 International License (http://creativecommons.org/licenses/by-nc/4.0/), which permits any noncommercial use, distribution, and reproduction in any medium, provided you give appropriate credit to the original author(s) and the source, provide a link to the Creative Commons license, and indicate if changes were made.

\section{References}

1. American Psychiatric Association. Diagnostic and statistical manual of mental disorders [Internet]. 5th ed. Washington, DC: American Psychiatric Association; 2013.

2. Van Ameringen M, Patterson BN, Simpson W. DSM-5 Obsessive-compulsive and related disorders: clinical implications of new criteria. Depress Anxiety. 2014;31:487-93.

3. Hasan A, Falkai P, Wobrock T, Lieberman J, Glenthøj B, Gattaz WF, et al. World Federation of Societies of Biological Psychiatry (WFSBP) guidelines for biological treatment of schizophrenia - a short version for primary care. Int J Psychiatry Clin Pract. 2017;21:82-90.

4. Öst L-G, Riise EN, Wergeland GJ, Hansen B, Kvale G. Cognitive behavioral and pharmacological treatments of OCD in children: a systematic review and meta-analysis. J Anxiety Disord. 2016;43:58-69.

5. Rapp AM, Bergman RL, Piacentini J, McGuire JF. Evidencebased assessment of obsessive-compulsive disorder. J Cent Nerv Syst Dis. 2016;8:13-29 (Internet Libertas Academica).
6. Frías Á, Palma C, Farriols N, González L. Comorbidity between obsessive-compulsive disorder and body dysmorphic disorder: prevalence, explanatory theories, and clinical characterization. Neuropsychiatr Dis Treat. 2015;11:2233-44.

7. Cororve MB, Gleaves DH. Body dysmorphic disorder: a review of conceptualizations, assessment, and treatment strategies. Clin Psychol Rev. 2001;21:949-70.

8. Phillips KA, Hollander E, Rasmussen SA, Aronowitz BR, DeCaria C, Goodman WK. A severity rating scale for body dysmorphic disorder: development, reliability, and validity of a modified version of the Yale-Brown Obsessive Compulsive Scale. Psychopharmacol Bull. 1997;33:17-22.

9. Christenson GA, Pyle RL, Mitchell JE. Estimated lifetime prevalence of trichotillomania in college students. J Clin Psychiatry. 1991;52:415-7.

10. Grant JE, Chamberlain SR. Trichotillomania. Am J Psychiatry. 2016;173:868-74.

11. Keuthen NJ, O'Sullivan RL, Ricciardi JN, Shera D, Savage CR, Borgmann AS, et al. The Massachusetts General Hospital (MGH) Hairpulling Scale: 1. Development and factor analyses. Psychother Psychosom. 1995;64:141-5.

12. Selles RR, McGuire JF, Small BJ, Storch EA. A systematic review and meta-analysis of psychiatric treatments for excoriation (skin-picking) disorder. Gen Hosp Psychiatry. 2016;41:29-37.

13. Mataix-Cols D. Hoarding disorder. N Engl J Med. 2014;370:2023-30.

14. American Psychiatric Association. Practice guideline for the treatment of patients with obsessive-compulsive disorder. Arlington, VA: American Psychiatric Association; 2007. http:// www.psych.org/psych_pract/treatg/pg/prac_guide.cfm.

15. The British Psychological Society. Obsessive- compulsive disorder: Core interventions in the treatment of obsessivecompulsive disorder and body dysmorphic disorder British Library Cataloguing-in-Publication Data. Br Psychol Soc R Coll Psychiatr. 2006.

16. Rothbart R, Amos T, Siegfried N, Ipser JC, Fineberg N, Chamberlain SR, et al. Pharmacotherapy for trichotillomania. In: Stein DJ, editor. Cochrane Database Syst Rev. 2013; https://doi. org/10.1002/14651858.cd007662.pub2

17. Van den Heuvel OA, van den Werf YD, van Verhoef KMW, de Wit S, Berendse HW, Wolters EC, et al. Frontal-striatal abnormalities underlying behaviours in the compulsive-impulsive spectrum. J Neurol Sci. 2010;289:55-9.

18. van den Heuvel OA, van Wingen G, Soriano-Mas C, Alonso P, Chamberlain SR, Nakamae T, et al. Brain circuitry of compulsivity. Eur Neuropsychopharmacol. 2016;26:810-27.

19. Gonçalves ÓF, Carvalho S, Leite J, Fernandes-Gonçalves A, Carracedo A, Sampaio A. Cognitive and emotional impairments in obsessive-compulsive disorder: evidence from functional brain alterations. Porto Biomed J. 2016;1:92-105.

20. Phillips ML, Drevets WC, Rauch SL, Lane R. Neurobiology of emotion perception I: The neural basis of normal emotion perception. Biol Psychiatry. 2003;54:504-14.

21. Phillips ML, Drevets WC, Rauch SL, Lane R. Neurobiology of emotion perception II: Implications for major psychiatric disorders. Biol Psychiatry. 2003;54:515-28.

22. Gillan CM, Robbins TW, Sahakian BJ, van den Heuvel OA, van Wingen G. The role of habit in compulsivity. Eur Neuropsychopharmacol. 2016;26:828-40.

23. Feusner JD, Yaryura-Tobias J, Saxena S. The pathophysiology of body dysmorphic disorder. Body Image. 2008;5:3-12.

24. Harries MD, Chamberlain SR, Redden SA, Odlaug BL, Blum AW, Grant JE. A structural MRI study of excoriation (skin-picking) disorder and its relationship to clinical severity. Psychiatry Res Neuroimaging. 2017;269:26-30. 
25. Li W, Arienzo D, Feusner JD. Body Dysmorphic disorder: neurobiological features and an updated model. Z Klin Psycho Psychother (Gott). 2013;42(3):184-91.

26. Stein DJ. Neurobiology of the obsessive-compulsive spectrum disorders. Biol Psychiatry. 2000;47:296-304.

27. Atmaca M, Bingol I, Aydin A, Yildirim H, Okur I, Yildirim MA, et al. Brain morphology of patients with body dysmorphic disorder. J Affect Disord. 2010;123:258-63.

28. Odlaug BL, Hampshire A, Chamberlain SR, Grant JE. Abnormal brain activation in excoriation (skin-picking) disorder: evidence from an executive planning fMRI study. Br J Psychiatry. 2016;208:168-74.

29. Kusumi I, Boku S, Takahashi Y. Psychopharmacology of atypical antipsychotic drugs: from the receptor binding profile to neuroprotection and neurogenesis. Psychiatry Clin Neurosci. 2005;69:243-58.

30. Shapiro DA, Renock S, Arrington E, Chiodo LA, Liu L-X, Sibley DR, et al. Aripiprazole, a novel atypical antipsychotic drug with a unique and robust pharmacology. Neuropsychopharmacology. 2003;28(8):1400-11.

31. Maeda K, Sugino H, Akazawa H, Amada N, Shimada J, Futamura T, et al. Brexpiprazole I. In vitro and in vivo characterization of a novel serotonin-dopamine activity modulator. J Pharmacol Exp Ther. 2014;350:589-604.

32. Shapiro DA, Renock S, Arrington E, Chiodo LA, Liu L-X, Sibley DR, et al. Aripiprazole, a novel atypical antipsychotic drug with a unique and robust pharmacology. Neuropsychopharmacology. 2003;28:1400-11.

33. Jensen NH, Rodriguiz RM, Caron MG, Wetsel WC, Rothman $\mathrm{RB}$, Roth BL. N-desalkylquetiapine, a potent norepinephrine reuptake inhibitor and partial 5-HT 1A agonist, as a putative mediator of quetiapine's antidepressant activity. Neuropsychopharmacology. 2008;33:2303-12.

34. Selent J, López L, Sanz F, Pastor M. Multi-receptor binding profile of clozapine and olanzapine: a structural study based on the new b 2 adrenergic receptor template. ChemMedChem. 2008;2:1194-8.

35. Meltzer HY. An overview of the mechanism of action of clozapine. J Clin Psychiatry. 1994;55 Suppl B:47-52.

36. Pessina E, Albert U, Bogetto F, Maina G. Aripiprazole augmentation of serotonin reuptake inhibitors in treatment-resistant obsessive-compulsive disorder: a 12-week open-label preliminary study. Int Clin Psychopharmacol. 2009;24:265-9.

37. Ak M, Bulut SD, Bozkurt A, Ozsahin A. Aripiprazole augmentation of serotonin reuptake inhibitors in treatment-resistant obsessive-compulsive disorder: a 10-week open-label study. Adv Ther. 2011;28:341-8

38. Muscatello MRA, Bruno A, Pandolfo G, Micò U, Scimeca G, Romeo VM, et al. Effect of aripiprazole augmentation of serotonin reuptake inhibitors or clomipramine in treatment-resistant obsessive-compulsive disorder: a double-blind, placebo-controlled study. J Clin Psychopharmacol. 2011;31:174-9.

39. Sayyah M, Sayyah M, Boostani H, Ghaffari SM, Hoseini A. Effects of aripiprazole augmentation in treatment-resistant obsessive-compulsive disorder (a double blind clinical trial). Depress Anxiety. 2012;29:850-4.

40. Delle Chiaie R, Scarciglia P, Pasquini M, Caredda M, Biondi M. Aripiprazole augmentation in patients with resistant obsessive compulsive disorder: a pilot study. Clin Pract Epidemiol Ment Health. 2011;7:107-11.

41. Segalas C, Alonso P, Real E, Lopez-Sola C, Estevez M, Menchon $\mathrm{J}$. Aripiprazole in obsessive-compulsive disorder: A case series of 71 patients refractory to other antipsychotics augmentation strategies. Eur Neuropsychopharmacol. 2013;82:S533-4.

42. Connor KM, Payne VM, Gadde KM, Zhang W, Davidson JRT. The use of aripiprazole in obsessive-compulsive disorder: preliminary observations in 8 patients. J Clin Psychiatry. 2005;66:49-51.

43. Selvi Y, Atli A, Aydin A, Besiroglu L, Ozdemir P, Ozdemir O. The comparison of aripiprazole and risperidone augmentation in selective serotonin reuptake inhibitor-refractory obsessivecompulsive disorder: a single-blind, randomised study. Hum Psychopharmacol Clin Exp. 2011;26:51-7.

44. Shoja Shafti S, Kaviani H. Aripiprazole versus quetiapine in treatment-resistant obsessive-compulsive disorder: a doubleblind clinical trial. Ther Adv Psychopharmacol. 2015;5:32-7.

45. Matsunaga H, Hayashida K, Maebayashi K, Mito H, Kiriike N. A case series of aripiprazole augmentation of selective serotonin reuptake inhibitors in treatment-refractory obsessive compulsive disorder. Int J Psychiatry Clin Pract. 2011;15:263-9.

46. Hegde A, Kalyani BG, Arumugham SS, Narayanaswamy JC, Math SB, Reddy YCJ. Aripiprazole augmentation in highly treatmentresistant obsessive-compulsive disorder-experience from a specialty clinic in India. Int J Psychiatry Clin Pract. 2017;21:67-9.

47. Patra S. Treat the disease not the symptoms: successful management of obsessive compulsive disorder in bipolar disorder with aripiprazole augmentation. Aust N Zeal J Psychiatry. 2016;50:809-10.

48. Hou Y-C, Lai C-H. Rapid responses of high-dose combined therapy of escitalopram and aripiprazole in a case of severe obsessive compulsive disorder with delusion. J Neuropsychiatry Clin Neurosci. 2014;26:E44-5.

49. da Rocha FF, Correa H. Successful augmentation with aripiprazole in clomipramine-refractory obsessive-compulsive disorder. Prog Neuro-Psychopharmacology Biol Psychiatry. 2007;31:1550-1.

50. Curtis AR, Richards RW. The Treatment of Psychogenic Excoriation and Obsessive Compulsive Disorder Using Aripiprazole and Fluoxetine. Ann Clin Psychiatry. 2007;19:199-200.

51. Izci F, Yalcin M, Kurtulus Calli SY, Sever Y, Bilici R. Aripiprazole augmentation of clomipramine therapy in treatment-resistant obsessive-compulsive disorder: case series. Dusunen Adam J Psychiatry Neurol Sci. 2016;32:167-72.

52. Ginsberg DL. Aripiprazole augmentation of clomipraminerefractory obsessive-compulsive disorder. Prim Psychiatry. 2007;14:19-20.

53. Takaki M. Aripiprazole as monotherapy at bedtime was effective for treatment of two cases of obsessive-compulsive disorder and insomnia. J Neuropsychiatry Clin Neurosci. 2014;26:E64.

54. Higuma H, Kanehisa M, Maruyama Y, Ishitobi Y, Tanaka Y, Tsuru J, et al. Aripiprazole augmentation in 13 patients with refractory obsessive-compulsive disorder: a case series. World J Biol Psychiatry. 2012;13:14-21.

55. Lai J, Lu Q, Zhang P, Xu T, Xu Y, Hu S. Aripiprazole augmentation in managing comorbid obsessive-compulsive disorder and bipolar disorder: a case with suicidal attempts. Neuropsychiatr Dis Treat. 2017;13:87-90.

56. Fornaro M, Gabrielli F, Mattei C, Vinciguerra V, Fornaro P. Aripiprazole augmentation in poor insight obsessive-compulsive disorder: a case report. Ann Gen Psychiatry. 2008. https://doi. org/10.1186/1744-859x-7-26.

57. Sarkar R, Klein J, Krüger S. Aripiprazole augmentation in treatment-refractory obsessive-compulsive disorder. Psychopharmacology. 2008;197:687-8.

58. Friedman S, Abdallah TA, Oumaya M, Rouillon F, Guelfi J-D. Aripiprazole augmentation of clomipramine-refractory obsessive-compulsive disorder. J Clin Psychiatry. 2007;68:972-3.

59. Ashton AK. Aripiprazole augmentation of combination escitalopram and sertraline in the treatment of refractory obsessivecompulsive disorder. Psychiatry (Edgmont). 2005;2:18.

60. Uguz F. Successful treatment of comorbid obsessive-compulsive disorder with aripiprazole in three patients with bipolar disorder. Gen Hosp Psychiatry. 2010;32:556-8. 
61. Pae C-U. Potential utility of aripiprazole monotherapy for the treatment of major depressive disorder comorbid with obsessivecompulsive disorder. Psychiatry Clin Neurosci. 2009;63:593.

62. Winter C, Heinz A, Kupsch A, Ströhle A. Aripiprazole in a case presenting with Tourette syndrome and obsessive-compulsive disorder. J Clin Psychopharmacol. 2008;28:452-4.

63. McDougle CJ, Barr LC, Goodman W, Pelton GH, Al E. Lack of efficacy of clozapine monotherapy in refractory obsessivecompulsive disorder. Am J Psychiatry. 1995;152:1812-4.

64. Young C, Bostic J, McDanald C. Clozapine and refractory obsessive-compulsive disorder: a Case Report. J Clin Psychiatry. 1994;14:209-10.

65. Steinert T, Schmidt-Michel WWPK. Considerable improvement in a case of obsessive-compulsive disorder in an emotionally unstable personality disorder, borderline type under treatment with clozapine. Pharmacopsychiatry. 1996;29:111-4.

66. Shapira NA, Ward HE, Mandoki M, Murphy TK, Yang MCK, Blier P, et al. A double-blind, placebo-controlled trial of olanzapine addition in fluoxetine-refractory obsessive-compulsive disorder. Biol Psychiatry. 2004;55:553-5.

67. Maina G, Pessina E, Albert U, Bogetto F. 8-week, single-blind, randomized trial comparing risperidone versus olanzapine augmentation of serotonin reuptake inhibitors in treatmentresistant obsessive-compulsive disorder. Eur Neuropsychopharmacol. 2008;18:364-72.

68. Matsunaga H, Nagata T, Hayashida K, Ohya K, Kiriike N, Stein DJ. A long-term trial of the effectiveness and safety of atypical antipsychotic agents in augmenting SSRI-refractory obsessivecompulsive disorder. J Clin Psychiatry. 2009;70:863-8.

69. Francobandiera G. Olanzapine augmentation of serotonin uptake inhibitors in obsessive-compulsive disorder: an open study. Can J Psychiatry. 2001;46:356-8.

70. Marazziti D, Pfanner C, Dell'Osso B, Ciapparelli A, Presta $\mathrm{S}$, Corretti G, et al. Augmentation strategy with olanzapine in resistant obsessive compulsive disorder: an Italian long-term open-label study. J Psychopharmacol. 2005;19:392-4.

71. Bogetto F, Bellino S, Vaschetto P, Ziero S. Olanzapine augmentation of fluvoxamine-refractory obsessive-compulsive disorder (OCD): a 12-week open trial. Psychiatry Res. 2000;96:91-8

72. Koran L, Ringold A, Elliott M. Olanzapine augmentation for treatment-resistant obsessive compulsive disorder. J Clin Psychiatry. 2000;61:514-7.

73. Crocq MA, Leclercq P, Guillon MS, Bailey PE. Open-label olanzapine in obsessive-compulsive disorder refractory to antidepressant treatment [1]. Eur Psychiatry. 2002;17:296-7.

74. D’Amico G, Cedro C, Muscatello MR, Pandolfo G, Di Rosa $\mathrm{AE}$, Zoccali R, et al. Olanzapine augmentation of paroxetinerefractory obsessive-compulsive disorder. Prog Neuro-Psychopharmacology Biol Psychiatry. 2003;27:619-23.

75. Poyurovsky M, Kurs R, Weizman A. Olanzapine-sertraline combination in schizophrenia with obsessive-compulsive disorder. J Clin Psychiatry. 2003;64:611.

76. Potenza MN, Wasylink S, Longhurst J, Neill Epperson C, McDougle CJ. Olanzapine Augmentation of fluoxetine in the treatment of refractory obsessive-compulsive disorder. J Clin Psychopharmacol. 1998;18:423-4.

77. Petrikis P, Andreou C, Bozikas V, Karavatos A. Effective use of olanzapine for obsessive-compulsive symptoms in a patient with bipolar disorder. Can J Psychiatry. 2004;49:572-3.

78. Marazziti D, Pallanti S. Effectiveness of olanzapine treatment for severe obsessive-compulsive disorder. Am J Psychiatry. 1999;156:1834-5.

79. Morrison D, Clark D, Goldfarb E, McCoy L. Worsening of obsessive-compulsive symptoms following treatment with olanzapine. Am J Psychiatry. 1998;155:855.
80. Ramasubbu R, Ravindran A, Lapierre Y. Serotonin and dopamine antagonism in obsessive-compulsive disorder: effect of atypical antipsychotic drugs. Pharmacopsychiatry. 2000;33:236-8.

81. Degner D, Bleich S, Kornhuber J, Ruther E. Olanzapine treatment of obsessive-compulsive disorder. Can J Psychiatry. 2000;45:393.

82. Marusic A, Farmer A. Antidepressant augmentation with lowdose olanzapine in obsessive-compulsive disorder. Br J Psychiatry. 2000;177:567.

83. Weiss E, Potenza MN, McDougle CJ, Neill Epperson C. Olanzapine addition in obsessive-compulsive disorder refractory to selective serotonin reuptake inhibitors: an open-label case series. J Clin Psychiatry. 1999;60:524-7.

84. Storch EA, Goddard AW, Grant JE, De Nadai AS, Goodman WK, Mutch PJ, et al. Double-blind, placebo-controlled, pilot trial of paliperidone augmentation in serotonin reuptake inhibitor-resistant obsessive-compulsive disorder. J Clin Psychiatry. 2013;74:e527-32.

85. Diniz JB, Shavitt RG, Fossaluza V, Koran L, Pereira CA, Miguel EC. A double-blind, randomized, controlled trial of fluoxetine plus quetiapine or clomipramine versus fluoxetine plus placebo for obsessive-compulsive disorder. J Clin Psychopharmacol. 2011;31:763-8.

86. Kordon A, Wahl K, Koch N, Zurowski B, Anlauf M, Vielhaber $\mathrm{K}$, et al. Quetiapine addition to serotonin reuptake inhibitors in patients with severe obsessive-compulsive disorder. J Clin Psychopharmacol. 2008;28:550-4.

87. Carey PD, Vythilingum B, Seedat S, Muller JE, van Ameringen M, Stein DJ. Quetiapine augmentation of SRIs in treatment refractory obsessive-compulsive disorder: a double-blind, randomised, placebo-controlled study [ISRCTN83050762]. BMC Psychiatry. 2005;5:5.

88. Fineberg NA, Sivakumaran T, Roberts A, Gale T. Adding quetiapine to SRI in treatment-resistant obsessive-compulsive disorder: a randomized controlled treatment study. Int Clin Psychopharmacol. 2005;20:223-6.

89. Bogan AM, Koran LM, Chuong HW, Vapnik T, Bystritsky A. Quetiapine augmentation in obsessive-compulsive disorder resistant to serotonin reuptake inhibitors: an open-label study. J Clin Psychiatry. 2005;66:73-9.

90. Atmaca M, Kuloglu M, Tezcan E, Gecici O. Quetiapine augmentation in patients with treatment resistant obsessive-compulsive disorder: a single-blind, placebo-controlled study. Int Clin Psychopharmacol. 2002;17:115-9.

91. Denys D, de Geus F, van Megen H, Westenberg HGM. A double-blind, randomized, placebo-controlled trial of quetiapine addition in patients with obsessive-compulsive disorder refractory to serotonin reuptake inhibitors. J Clin Psychiatry. 2004;65:1040-8.

92. Vulink NCC, Denys D, Fluitman SBAHA, Meinardi JCM, Westenberg HGM. Quetiapine augments the effect of citalopram in non-refractory obsessive-compulsive disorder: a randomized, double-blind, placebo-controlled study of 76 patients. J Clin Psychiatry. 2009;70:1001-8.

93. Savas HA, Yumru M, Ozen ME. Quetiapine and ziprasidone as adjuncts in treatment-resistant obsessive-compulsive disorder: a retrospective comparative study. Clin Drug Investig. 2008;28:439-42.

94. Francobandiera G. Quetiapine augmentation of sertraline in obsessive-compulsive disorder. J Clin Psychiatry. 2002;63:1046-7.

95. Dell'Osso B, Mundo E, Altamura AC. Quetiapine augmentation of selective serotonin reuptake inhibitors in treatment-resistant obsessive-compulsive disorder: a six-month follow-up case series. CNS Spectr. 2006;11:879-83 (quiz 885). 
96. Menaster M. Efficacy of quetiapine in panic disorder with agoraphobia and obsessive-compulsive disorder in a patient with bipolar disorder. Psychiatry (Edgmont). 2005;2:17-8.

97. Foa EB, Simpson HB, Rosenfield D, Liebowitz MR, Cahill SP, Huppert JD, et al. Six-month outcomes from a randomized trial augmenting serotonin reuptake inhibitors with exposure and response prevention or risperidone in adults with obsessivecompulsive disorder. J Clin Psychiatry. 2015;440-6.

98. Simpson HB, Foa EB, Liebowitz MR, Huppert JD, Cahill S, Maher MJ, et al. Cognitive-behavioral therapy vs risperidone for augmenting serotonin reuptake inhibitors in obsessive-compulsive disorder. JAMA Psychiatry. 2013;70:1190 (American Medical Association).

99. Wheaton MG, Rosenfield D, Foa EB, Simpson HB. Augmenting serotonin reuptake inhibitors in obsessive-compulsive disorder: what moderates improvement? J Consult Clin Psychol. NIH Public Access. 2015;83:926-37.

100. Hegde A, Kalyani BG, Arumugham SS, Narayanaswamy JC, Math SB, Reddy YCJ. Effectiveness of risperidone augmentation in obsessive-compulsive disorder. J Clin Psychopharmacol. 2016;36:381-4.

101. Hollander E, Rossi NB, Sood E, Pallanti S. Risperidone augmentation in treatment-resistant obsessive-compulsive disorder: a double-blind, placebo-controlled study. Int J Neuropsychopharmacol. 2003;6:S1461145703003730.

102. McDougle CJ, Epperson CN, Pelton GH, Wasylink S, Price LHJHG, et al. A double-blind, placebo-controlled study of risperidone addition in serotonin reuptake inhibitor-refractory obsessive-compulsive disorder. Arch Gen Psychiatry. 2000;57:794.

103. Erzegovesi S, Guglielmo E, Siliprandi F, Bellodi L. Low-dose risperidone augmentation of fluvoxamine treatment in obsessivecompulsive disorder: a double-blind, placebo-controlled study. Eur Neuropsychopharmacol. 2005;15:69-74.

104. Pfanner C, Marazziti D, Dell'Osso L, Presta S, Gemignani A, Milanfranchi A, et al. Risperidone augmentation in refractory obsessive compulsive disorder: an open-label study. Eur Neuropsychopharmacol. 2000;10:349-50.

105. Saxena S, Wang D, Bystritsky A, Baxter L. Risperidone augmentation of SRI treatment for refractory obsessive-compulsive disorder. J Clin Psychiatry. 1996;57:303-6 (Physicians Postgraduate Press).

106. Li X, May RS, Tolbert LC, Jackson WT, Flournoy JM, Baxter LR. Risperidone and haloperidol augmentation of serotonin reuptake inhibitors in refractory obsessive-compulsive disorder : a crossover study. J Clin Psychiatry. 2005;66:736-43.

107. McDougle CJ, Fleischmann RL, Epperson CN, Wasylink S, Leckman JF, Price LH. Risperidone addition in fluvoxaminerefractory obsessive-compulsive disorder: three cases. J Clin Psychiatry. 1995;56:526-8.

108. Yoshimura R, Kaneko S, Shinkai K, Nakamura J. Successful treatment for obsessive-compulsive disorder with addition of low-dose risperidone to fluvoxamine: implications for plasma levels of catecholamine metabolites and serum brainderived neurotrophic factor levels. Psychiatry Clin Neurosci. 2006;60:389-93.

109. Kawahara T, Ueda Y, Mitsuyama Y. A case report of refractory obsessive-compulsive disorder improved by risperidone augmentation of clomipramine treatment. Psychiatry Clin Neurosci. 2000;54:599-601.

110. Sun T, Lin P, Wu C. Risperidone augmentation of specific serotonin reuptake inhibitors in the treatment of refractory obsessivecompulsive disorder: report of two cases. Chang Gung Med J. 2001;24:587-92.

111. Ravizza L, Barzega G, Bellino S, Bogetto F, Maina G. Therapeutic effect and safety of adjunctive risperidone in refractory obsessive-compulsive disorder (OCD). Psychopharmacol Bull. 1996;32:677-82.

112. Stein DJ, Bouwer C, Hawkridge S, Emsley RA. Risperidone augmentation of serotonin reuptake inhibitors in obsessive-compulsive and related disorders. J Clin Psychiatry. 1997;58:119-22.

113. Agid O, Lerer B. Risperidone augmentation of paroxetine in a case of severe, treatment-refractory obsessive-compulsive disorder without comorbid psychopathology. J Clin Psychiatry. 1999;60:55-6.

114. Andrade C. Risperidone may worsen fluoxetine-treated OCD. J Clin Psychiatry. 1998;59:255-6.

115. Bruno A, Pandolfo G, Cedro C, Gallo G, De Felice M, Zoccali RA, et al. Effect of ziprasidone augmentation of serotonin reuptake inhibitors in treatment-resistant obsessive-compulsive disorder. Clin Neuropharmacol. 2016;39:6-9.

116. Bloch MH, Landeros-Weisenberger A, Kelmendi B, Coric V, Bracken MB, Leckman JF. A systematic review: antipsychotic augmentation with treatment refractory obsessive-compulsive disorder. Mol Psychiatry. 2006;11:622-32.

117. Skapinakis P, Papatheodorou T, Mavreas V. Antipsychotic augmentation of serotonergic antidepressants in treatmentresistant obsessive-compulsive disorder: a meta-analysis of the randomized controlled trials. Eur Neuropsychopharmacol. 2007;17:79-93.

118. Komossa K, Depping AM, Meyer M, Kissling W, Leucht S. Second-generation antipsychotics for obsessive compulsive disorder. In: Komossa K, editor. Cochrane Database Syst Rev. 2010. https ://doi.org/10.1002/14651858.cd008141.pub2.

119. Maglione M, Ruelaz Maher A, Hu J, Wang Z, Shanman R, Shekelle PG, Roth B, Hilton L, Suttorp MJ, Ewing BA, Motala A, Perry T. Off-label use of atypical antipsychotics: an update. Rockville, MD: Agency for Healthcare Research and Quality; 2011. http://www.effectivehealthcare.ahrq.gov/reports/final.cfm.

120. Dold M, Aigner M, Lanzenberger R, Kasper S. Antipsychotic augmentation of serotonin reuptake inhibitors in treatment-resistant obsessive- compulsive disorder: an update meta-analysis of double-blind, randomized, placebo-controlled trials. Int J Neuropsychopharmacol. 2015;18:1-11.

121. Dold M, Aigner M, Lanzenberger R, Kasper S. Antipsychotic augmentation of serotonin reuptake inhibitors in treatment-resistant obsessive-compulsive disorder: a meta-analysis of doubleblind, randomized, placebo-controlled trials. Int J Neuropsychopharmacol. 2013;16:557-74.

122. Maher AR, Maglione M, Bagley S, Suttorp M, Hu J-H, Ewing $\mathrm{B}$, et al. Efficacy and comparative effectiveness of atypical antipsychotic medications for off-label uses in adults. JAMA. 2011;306:1359-69.

123. Veale D, Miles S, Smallcombe N, Ghezai H, Goldacre B, Hodsoll J. Atypical antipsychotic augmentation in SSRI treatment refractory obsessive-compulsive disorder: a systematic review and meta-analysis. BMC Psychiatry. 2014;14:317.

124. National Collaborating Centre for Mental Health. Obsessivecompulsive disorder and body dysmorphic disorder: treatment. Natl Inst Heal Clin Excell. 2006. National Clinical Practice Guideline Number 31.

125. Uzun O, Ozdemir B. Aripiprazole as an augmentation agent in treatment-resistant body dysmorphic disorder. Clin Drug Investig. 2010;30:707-11.

126. Phillips KA. Olanzapine augmentation of fluoxetine in body dysmorphic disorder. Am J Psychiatry. 2005;162:1022-3.

127. Nakaaki S, Murata Y, Furukawa TA. Efficacy of olanzapine augmentation of paroxetine therapy in patients with severe body dysmorphic disorder. Psychiatry Clin Neurosci. 2008;62:370.

128. Grant JE. Successful treatment of nondelusional body dysmorphic disorder with olanzapine: a case report. J Clin Psychiatry. 2001;62:297-8. 
129. Diniz JB, Costa DL, Cassab RC, Pereira CA, Miguel EC, Shavitt RG. The impact of comorbid body dysmorphic disorder on the response to sequential pharmacological trials for obsessivecompulsive disorder. J Psychopharmacol. 2014;28:603-11.

130. Goulia P, Mantas C, Bassukas ID, Hyphantis T. Treatment with risperidone and venlafaxine of a patient with double-coded diagnosis of body dysmorphic disorder and delusional disorder somatic type. Hippokratia. 2011;15:286-7.

131. Vilaverde D, Gonçalves J, Morgado P. Hoarding disorder: a case report. Front Psychiatry. 2017;8:112.

132. Kaplan A, Hollander E. Comorbidity in compulsive hoarding: a case report. CNS Spectr. 2004;9:71-3.

133. Chong SA, Tan CH, Lee HS. Hoarding and clozapine-risperidone combination. Can J Psychiatry. 1996;41:315-6.

134. White MP, Koran LM. Open-label trial of aripiprazole in the treatment of trichotillomania. J Clin Psychopharmacol. 2011;31:503-6.

135. Howard AK, Krishnamoorthy A, Leavitt BR, Raymond LA, Weissman CR. Treatment of Huntington disease and comorbid trichotillomania with aripiprazole. J Neuropsychiatry Clin Neurosci. 2015;27:e211-2.

136. Virit O, Selek S, Savas HA, Kokaçya H. Improvement of restless legs syndrome and trichotillomania with aripiprazole. J Clin Pharm Ther. 2009;34:723-5.

137. Jefferys D, Burrows G. Reversal of trichotillomania with aripiprazole. Depress Anxiety. 2008;25:E37-40.

138. Yasui-Furukori N, Kaneko S. The efficacy of low-dose aripiprazole treatment for trichotillomania. Clin Neuropharmacol. 2011;34:258-9.

139. Van Ameringen M, Mancini C, Patterson B, Bennett M, Oakman J. A randomized, double-blind, placebo-controlled trial of olanzapine in the treatment of trichotillomania. J Clin Psychiatry. 2010;71:1336-43.

140. Stewart RS, Nejtek VA. An open-label, flexible-dose study of olanzapine in the treatment of trichotillomania. J Clin Psychiatry. 2003;64:49-52.

141. Gupta M, Gupta AK. Olanzapine is effective in the management of some self-induced dermatoses: three case reports. Cutis. 2000;66:143-6.

142. Srivastava RK, Sharma S, Tiwari N, Saluja B. Olanzapine augmentation of fluoxetine in trichotillomania: two cases. Aust N Z J Psychiatry. 2005;39:112-3.

143. Potenza MN, Wasylink S, Neill Epperson C, McDougle CJ. Olanzapine augmentation of fluoxetine in the treatment of trichotillomania. Am J Psychiatry. 1998;155:1299-300.

144. Ashton AK. Olanzapine augmentation for trichotillomania. Am J Psychiatry. 2001;158:1929-30.
145. Crescente Junior JAB, Guzman CS, Tavares H. Quetiapine for the treatment of trichotillomania. Rev Bras Psiquiatr. 2008;30:402.

146. Jones GC, Coutinho K, Anjaria D, Hussain N, Dholakia R. Treatment of Recurrent Rapunzel Syndrome and Trichotillomania: case Report and Literature Review. Psychosomatics. 2010;51:443-6.

147. Khouzam HR, Battista MA, Byers PE. An overview of trichotillomania and its response to treatment with quetiapine. Psychiatry. 2002;65:261-70.

148. Senturk V, Tanriverdi N. Resistant trichotillomania and risperidone. Psychosomatics. 2002;43:439-42.

149. Gabriel A. A case of resistant trichotillomania treated with risperidone-augmented fluvoxamine. Can J Psychiatry. 2001;46:285-6.

150. Oravecz R, Štuhec M, Ko SM, Cohen LJ, Stein DJ, Simeon D, et al. Trichotillomania successfully treated with risperidone and naltrexone: a geriatric case report. J Am Med Dir Assoc Elsevier. 2014;15:301-2.

151. Epperson CN, Fasula D, Wasylink S, Price LH, McDougle CJ. Risperidone addition in serotonin reuptake inhibitor-resistant trichotillomania: three cases. J Child Adolesc Psychopharmacol. 1999;9:43-9.

152. Carter WG, Shillcutt SD. Aripiprazole augmentation of venlafaxine in the treatment of psychogenic excoriation. J Clin Psychiatry. 2006;67:1311.

153. Turner GA, Sutton S, Sharma A. Augmentation of venlafaxine with aripiprazole in a case of treatment-resistant excoriation disorder. Innov Clin Neurosci. 2014;11:29-31.

154. Christensen RC. Olanzapine augmentation of fluoxetine in the treatment of pathological skin picking. Can J Psychiatry. 2004;49:788-9.

155. Blanch J, Grimalt F, Massana G, Navarro V. Efficacy of olanzapine in the treatment of psychogenic excoriation. Br J Dermatol. 2004;151:714-6.

156. Arnold LM, Auchenbach MB, McElroy SL. Psychogenic excoriation. Clinical features, proposed diagnostic criteria, epidemiology and approaches to treatment. CNS Drugs. 2001;15:351-9.

157. Bax L, Moons KG. Beyond publication bias. J Clin Epidemiol. 2011;64:459-62.

158. Newcomer JW. Second-generation (atypical) antipsychotics and metabolic effects. CNS Drugs. 2005;19(Suppl 1):1-92.

159. Potenza MN, McDougle CJ. Potential of atypical antipsychotics in the treatment of nonpsychotic disorders. CNS Drugs. 1998;9:213-32. 